\title{
Joint altimetric and in-situ data assimilation using the GRACE mean dynamic topography: a 1993-1998 hindcast experiment in the Tropical Pacific Ocean
}

\author{
Frédéric Castruccio, Jacques Verron, Lionel Gourdeau, Jean-Michael Brankart, Pierre Brasseur
}

\begin{abstract}
The altimetric satellite signal is the sum of the geoid and the dynamic topography, but only the latter is relevant to oceanographic applications. Poor knowledge of the geoid has prevented oceanographers from fully exploiting altimetric measurements through its absolute component, and applications have concentrated on ocean variability through analyses of sea level anomalies. Recent geodetic missions like CHAMP, GRACE and the forthcoming GOCE are changing this perspective. In this study, data assimilation is used to reconstruct the Tropical Pacific Ocean circulation during the 1993-1996 period. Multivariate observations are assimilated into a primitive equation ocean model (OPA) using a reduced order Kalman filter (the Singular Evolutive Extended Kalman filter). A 6-year (1993-1998) hindcast experiment is analyzed and validated by comparison with observations. In this experiment, the new capability offered by an observed absolute dynamic topography (built using the GRACE geoid to reference the altimetric data) is used to assimilate, in an efficient way, the in-situ temperature profiles from the TAO/TRITON moorings together with the T/P and ERS1\&2 altimetric signal. GRACE
\end{abstract}

F. Castruccio $(\bowtie)$ · J. Verron · J.-M. Brankart · P. Brasseur Laboratoire des Ecoulements Géophysiques et Industriels, Université de Grenoble, BP 53X,

38041 Grenoble Cedex 09, France

e-mail: frederic.castruccio@hmg.inpg.fr

L. Gourdeau

Laboratoire d'Etudes en Géophysique et Océanographie Spatiales, Institut de recherche pour le développement, BP A5, 98848 Nouméa Cedex, New Caledonia, France data improves compatibility between both observation data sets. The difficulties encountered in this regard in previous studies such as Parent et al. (J Mar Syst 40-41: 381-401, 2003) are now circumvented. This improvement helps provide more efficient data assimilation, as evidenced, by assessing the results against independent data. This leads in particular to significantly more realistic currents and vertical thermal structures.

Keywords Altimetric data • Gravimetric data • Ocean modeling - Data assimilation - Tropical Pacific • Kalman filter

\section{Introduction}

For the past 15 years, altimetric satellites have provided high-precision, high-resolution, and quasisynoptic observations of sea surface height (SSH), representing the height of the sea level above a reference ellipsoid (Fig. 1). This SSH has two components: (1) the dynamic topography (DT), which represents the signature of the ocean circulation, and (2) the geoid, which reflects the earth's field of gravity. Poor knowledge of the geoid has prevented, and still prevents, oceanographers from fully exploiting the altimetric signal (Nerem et al. 1994). Only the temporal mean of the $\mathrm{SSH}$, the mean sea surface (MSSH), is known with precision (Hernandez et al. 2001). It corresponds to the sum of the geoid and of the mean dynamic topography (MDT), which reflects the mean circulation of the oceans. It is this MSSH that is taken from the $\mathrm{SSH}$, thereby providing access to the variable part of the ocean signal, that is the sea level anomaly (SLA), which is known with a centimetric precision. 
Fig. 1 Altimetric measurement principle

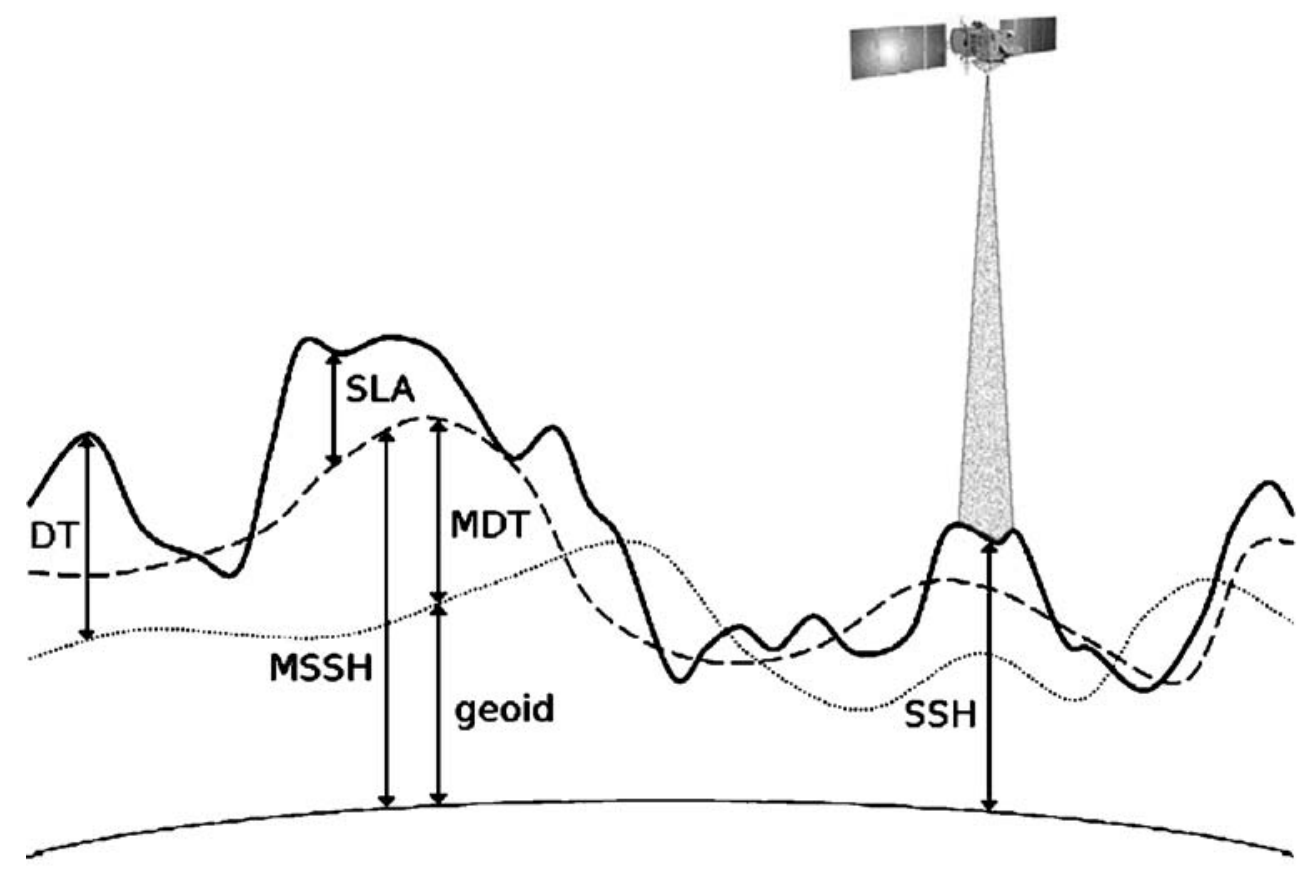

Since the launch of the first altimetric satellites, altimetric residuals have been widely used by the oceanographic community to better understand the ocean system, as well as its variability at different spatial and temporal scales (e.g., $\mathrm{Fu}$ and Cazenave 2001). However, almost 15 years after the launch of TOPEX/POSEIDON, the deduction of DT from altimetric measurements is still a challenge. To reconstruct this absolute dynamic topography from the sea level anomalies, a precise estimate of the MDT is required and, therefore, a precise knowledge of the geoid. The lack of such a good mean dynamic topography is a recurrent problem for the assimilation of altimetric data and the validity of numerical simulations (Blayo et al. 1994, 1997; Birol et al. 2004). Several methods have been developed to estimate the ocean MDT independently of the knowledge of the small-scale features of the geoid (e.g. Mercier 1986; Levitus et al. 1994; Levitus and Boyer 1994; Le Grand et al. 1998, 2003; Niiler et al. 2003; Rio and Hernandez 2004; Maximenko and Niiler 2005). However, none of the solutions has been fully satisfactory, and significant errors remain on the reference MDT (Rio et al. 2006). The definition of such a reference mean sea level also appears to be a crucial issue when dealing with assimilation of multiple source data. For example, Parent et al. (2003) (hereafter P03), concluded that the joint assimilation of altimetric and in-situ data exhibited poor results in their study because of the differences in the reference mean state between the two types of data.
The CHAMP mission launched in July 2000 was the first of a series of geodesic missions whose primary goal is to obtain precise knowledge of the terrestrial geoid. It was followed by the GRACE mission, launched in 2002. The upcoming GOCE mission should provide us with access to the small-scale features of the geoid that are needed to calculate a realistic mean dynamic topography, consistent with the SLA. Centimetric precision for a spatial resolution of $100-\mathrm{km}$ is expected. The GRACE and GOCE missions are complementary: GRACE is dedicated to long and medium wavelengths and to temporal variations of the geoid, while GOCE will provide higher resolutions. The substantial improvements in our knowledge of the terrestrial geoid resulting from the CHAMP mission and even more from the GRACE mission mean that today it is possible to consider purely satellite absolute altimetric signal for oceanographic applications (Gourdeau et al. 2003) and especially to assimilate data into realistic ocean models. This latter point is the subject of the present work.

This paper follows a series of earlier studies (Verron et al. 1999; Gourdeau et al. 2000; Durand et al. 2003; P03; Castruccio et al. 2006) on controlling the circulation in the Tropical Pacific region by data assimilation method based on the Singular Evolutive Extended Kalman (SEEK) filter proposed by Pham et al. (1998b). These studies demonstrated that the SEEK filter provides an effective control of annual and interannual variability in this region. They also highlight the limit 
of using a simple model MDT for referencing the SLA data. The preliminary work by Castruccio et al. (2006) shows that the use of an observed MDT instead of a model MDT allows one to make the most of the complementarity of satellite and in situ observations when assimilated together.

The aim of this work is to reconstruct, via data assimilation, the Tropical Pacific Ocean circulation during the 1993-1998 period by exploiting the complementarity between absolute altimetric data, referenced to the GRACE geoid, and in-situ data. The investigation is conducted in the region of the Tropical Pacific where a set of easily accessed and quasisynoptic in situ data (from the TAO/TRITON moorings) is available for the entire study period.

A 6-year hindcast experiment over the 1993-1998 period has been implemented and conducted. The TOPEX/POSEIDON and ERS1\&2 along-track SLA are referenced with the purely satellite-based mean dynamic topography deduced from GRACE gravimetric data. The assimilated dynamic topography thus exhibits a different temporal mean from the dynamic topography simulated by the free run model, which suggests a specific parameterization of the assimilation system. The SSH reconstructed in this way are assimilated every 5 days jointly with the daily temperature profiles collected by the TAO/TRITON moorings, in a primitive equation ocean global circulation model (OGCM). The assimilation system used is based on the SEEK filter. The objective of this paper is to present the implementation of this experiment and to describe the first global oceanic results over the period, which includes the strong El Niño/La Niña event of 19971998. It is worth noting that this 1997-1998 El Niño/La Niña event is especially challenging for assimilation techniques.

The paper is constructed as follows: Model, assimilation method, and assimilated data are described in Section 2. Section 3 focuses on the issues of the mean reference level for assimilation of the altimetric data. The results of the 6-year hindcast experiment with joint assimilation of altimetric and in-situ data are presented in Section 4. Section 5 discusses and provides a summary of the results.

\section{Assimilation experiment}

\subsection{Model}

Assimilation experiments were performed using the OPA (ocean parallelize) OGCM originally developed at LOCEAN (http://www.lodyc.jussieu.fr/NEMO). The configuration used is the so-called ORCA2 global freesurface version (Roulet and Madec 2000). ORCA2 is a low-resolution configuration using a $2^{\circ} \times 2^{\circ}$ ORCAtype grid with a variable meridional resolution varying from $0.5^{\circ}$ at the equator to $2^{\circ}$ poleward of $20^{\circ}$ latitude to better resolve the equatorial dynamics.

The model uses a turbulent kinetic energy closure model to parameterize the vertical mixing of momentum and tracer (Blanke and Delecluse 1993). The lateral mixing for active tracer (temperature and salinity) is parameterized along isopycnal surfaces.

The model is forced at the surface boundary with heat, freshwater, and momentum fluxes. In tropical oceans, the ocean dynamics is critically governed by wind stresses (Grima et al. 1999). This is why it is of primary importance to have adequate wind stress fields to force ocean models. In this study, the ERS scatterometer wind stresses are used and are complemented by TAO/TRITON derived stresses (Menkes et al. 1998). These wind stresses tend to produce more realistic thermocline and zonal currents. The heat and fresh water fluxes are computed on-line through bulk formulae during model integration and depend on prognostic sea surface temperature (SST) and NCEP atmospheric interannual data provided by NOAA. The observed monthly mean precipitation field from Xie and Arkin (1996) is used instead of NCEP rainfall. No local feedback term is added to account for the coupling between the surface ocean heat flux and the SST, as it is computed on-line. However, a restoring term is applied on sea surface salinity to avoid unrealistic drift due to our poor knowledge of fresh water fluxes.

This model has been used extensively for various Tropical Pacific studies and has been validated accordingly (e.g., Grima et al. 1999; Lengaigne et al. 2002, 2003; Alory et al. 2005; de Boyer Montégut et al. 2007). Starting from rest with the Levitus temperature and salinity data (Levitus et al. 1998), the model is spun up over 2 years using a climatological forcing calculated from the 1993-1998 interannual forcing fields. To limit drift in the mean thermohaline structure, a Newtonian damping term is added in the temperature and salinity equations during spin up. Then, an internannual simulation for the period 1993-1998 is conducted.

\subsection{Assimilation method}

SEEK filter The assimilation method used in this study is derived from the SEEK filter (Pham et al. 1998a, b). This sequential method has already been described and used in various types of studies (e.g., Verron et al. 1999; Gourdeau et al. 2000; P03; Durand et al. 2003; Brankart et al. 2003; Birol et al. 2004). 
A recent review of the development of the SEEK filter method for data assimilation (hereafter DA) in oceanography can be found in Brasseur and Verron (2006). With regard to the specific region of the Tropical Pacific Ocean, the SEEK filter has been validated within the framework of a twin experiment by Verron et al. (1999). It has also been applied with some success to real situations (e.g., Gourdeau et al. 2000; P03). The main aim of using such an approach is to reduce the enormous computing requirements to an acceptable level. This is achieved essentially by approximating the error covariance matrix by a singular low-rank matrix. This not only reduces implementation costs but may also improve filter stability, as corrections are only applied along the main directions of error in the system (Pham et al. 1998b). In the original version, the error basis is allowed to evolve over time according to nonlinear model dynamics, which constitutes the most original feature of the SEEK filter. Following Pham et al. (1998b), a convenient, but not unique, method for initializing the error covariance matrix is to use a limited number $r$ of three-dimensional, multivariate empirical orthogonal functions (EOFs) describing the dominant modes of free-model variability $(r \ll n$, where $n$ is the dimension of the state vector). In this case, the initial covariance matrix can be represented as:

$\mathbf{P}=\mathbf{N} \boldsymbol{\Lambda} \mathbf{N}^{T}=\mathbf{N} \Lambda^{1 / 2} \Lambda^{1 / 2} \mathbf{N}^{T}=\mathbf{S S}^{T}$

where the columns of $\mathbf{N}$ are formed by the $r$ orthonormalized eigenvectors of $\mathbf{P}$ and $\boldsymbol{\Lambda}$ is a diagonal matrix formed with the corresponding eigenvalues.

The analysis state $\mathbf{x}_{i}^{a}$ at time $t_{i}$ is computed from the forecast state $\mathbf{x}_{i}^{f}$, the set of observations $\mathbf{y}_{i}$, and the corresponding variables $\mathbf{H}_{i} \mathbf{x}_{i}^{f}$, where $\mathbf{H}_{i}$ is the observation operator at time $t_{i}$, by

$\mathbf{x}_{i}^{a}=\mathbf{x}_{i}^{f}+\mathbf{K}_{i}\left[\mathbf{y}_{i}-\mathbf{H}_{i} \mathbf{x}_{i}^{f}\right]$

The optimal state $\mathbf{x}_{i}^{a}$ is obtained by correcting the forecast $\mathbf{x}_{i}^{f}$ with a weighted measure of the misfit between the observations and the prior estimate (i.e., the innovation $\mathbf{y}_{i}-\mathbf{H}_{i} \mathbf{x}_{i}^{f}$ ). The weight matrix $\mathbf{K}_{i}$

$\mathbf{K}_{i}=\mathbf{P}_{i}^{f} \mathbf{H}_{i}^{T}\left(\mathbf{H}_{i} \mathbf{P}_{i}^{f} \mathbf{H}_{i}^{T}+\mathbf{R}_{i}\right)^{-1}$

is the so-called Kalman gain, which involves the forecast $\mathbf{P}_{i}^{f}$ and observation $\mathbf{R}_{i}$ error covariance matrices. It can be rewritten as:

$\mathbf{K}_{i}=\mathbf{S}_{i}\left[\mathbf{I}+\left(\mathbf{H}_{i} \mathbf{S}_{i}\right)^{T} \mathbf{R}_{i}^{-1}\left(\mathbf{H}_{i} \mathbf{S}_{i}\right)\right]^{-1}\left(\mathbf{H}_{i} \mathbf{S}_{i}\right)^{T} \mathbf{R}_{i}^{-1}$

The Kalman gain can be interpreted as the ratio between the error variance of the forecast and the total error variance (the sum of the forecast error variance and the observation error variance) projected in the observation space: the larger the forecast errors, the larger the correction to the forecast. The analysis step can be seen as a correction to the forecast step made from a combination of the EOFs with a weight proportional to the projection of the innovation vector.

As stated earlier, the reduced basis is normally allowed to evolve over time according to model dynamics. The time evolution of the basis seems to be particularly beneficial in midlatitudes where the physics is strongly nonlinear (Brasseur et al. 1999). In the tropical oceans, such additional features were actually found to have no significant impact. The improvements in results were not worthwhile with regard to the increase of the numerical cost (Verron et al. 1999). In the present implementation, the error subspace basis is therefore assumed to be temporally persistent, as in work by Gourdeau et al. (2000) and P03.

We also make use of the local variant of the SEEK filter described in Brankart et al. (2003) and Testut et al. (2003). The weak correlations associated with distant variables, which are considered as irrelevant in the reduced space, are set to zero. The analysis for each water column will therefore only depend on the observations within a specific influence bubble. A box of 15 by 9 grid points, respectively, in longitude and latitude is used to take into account the anisotropic nature of Tropical Pacific dynamics.

Continuous data assimilation In addition to the regular SEEK filter procedure, an incremental scheme was implemented. Indeed, a significant drawback of sequential methods is the time discontinuity of the solution resulting from intermittent corrections of the model state. This discontinuity can lead to spurious high-frequency oscillations and data rejection. To tackle these problems, Bloom et al. (1996) have proposed an algorithm called incremental analysis update (IAU) that acts like a continuous DA method. The principle is to incorporate the sequential analysis increment $\delta x=V^{a}-V^{f}$ directly in prognostic equations of the model as an additional forcing term:

$\frac{\partial V}{\partial t}=M+\gamma(t)\left(V^{a}-V^{f}\right)$

where $M$ are the right-hand-side members of the prognostic equation of the state variable $V$ and $\gamma$ is a parameter such that:

$$
{ }_{0}^{\Delta t} \gamma(t) d t=1
$$

$\Delta t$ being the duration of the assimilation cycle. 
An extensive description of the IAU algorithm used in this study can be found in Ourmières et al. (2006). The only difference with the scheme described in this paper is that, here, the IAU increment is applied on the four prognostic variables of the model, i.e., temperature, salinity, meridional, and zonal velocity.

Parameterization of the error covariances The assimilation sequence must be initialized with some initial guesses for the state $\mathbf{x}_{0}$ and the associated error covariance matrix $\mathbf{P}_{0}$. The initialization of $\mathbf{P}$ critically determines the functioning of the first assimilation stages through the process of error dynamics, initially (Ballabrera-Poy et al. 2001) and all along the process for a "fixed" SEEK filter. Initializing the error covariance matrix by using a limited number of threedimensional, multivariate EOFs describing the dominant modes of free-model variability has frequently been used to initialize Kalman filters in the Tropical Pacific Ocean (e.g. Cane et al. 1996; Verron et al. 1999; Gourdeau et al. 2000). One of the underlying hypothesis is that the model variability is representative of the true ocean variability and that the error statistics can be estimated from the ocean model variability.

With an absolute altimetric signal, the type of error one tries to correct is not simply a rephasing of the initial condition or the control of the variability signal. Assimilation of an absolute altimetry also implies control of the mean model state. This leads us to develop a specific protocol to parameterize the reduced order forecast error covariance matrix $\mathbf{P}^{f}$ of the SEEK filter. Instead of using EOFs of model variability to parameterize $\mathbf{P}^{f}$, we then decided to use an ensemble procedure to identify an adequate reduced space for $\mathbf{P}^{f}$. To do this, we first assume that a free model (without assimilation) simulation with a strong relaxation towards climatological fields provides a good approximation of the mean true ocean. In this reference simulation, model temperature and salinity are nudged towards the monthly Levitus climatology (using a 1-day time scale), and surface model velocity is nudged towards the surface geostrophic velocity deduced from GRACE MDT. Then, by using this reference run to reinitialize the free run every 5 days over 1 year, an ensemble of differences between this reference simulation and the free model 5-day forecasts without nudging is generated. This ensemble of 73 members represents the 5-day forecast error between the model and the reference trajectory. The covariance of this ensemble is then expected to be a good estimator of the 5-day model error covariance, which turns out to be adequate to parameterize the SEEK filter. The rank of this error covariance matrix is further reduced using a limited number (30) of three-dimensional, multivariate empirical orthogonal functions (EOFs) describing the dominant modes of the ensemble covariance.

With regard to the parameterization of observation errors covariance matrix $\mathbf{R}$, a diagonal matrix is used with standard deviations of $5 \mathrm{~cm}$ and $0.4^{\circ} \mathrm{C}$, respectively, for altimetry and temperature data. In the context of such a reduced order analysis, $\mathbf{R}$ is the sum of three different contributions: (1) the measurement error, (2) the representativity error (which is the fraction of the true signal that is not representable by the model), and (3) the truncation error (which is the fraction of the background error that is not included in the analysis reduced space). Providing a realistic estimation of $\mathbf{R}$ is thus a difficult task, and no standard method is available in the literature. The values used here are just an estimation of the three components constituting the observation errors covariance matrix $\mathbf{R}$.

\subsection{Data sets for assimilation}

Altimetric data The assimilated altimetric observations consist of along-track sea surface topography, obtained as the sum of along-track TOPEX/POSEIDON and/or ERS altimeter SLA, and the mean dynamic topography (see next section). The assimilation window is 5 days. Each analysis is computed using all the available data gathered within a 5-day interval (2.5 days before and after the analysis time). The accuracy of the SLA can be estimated at around $3 \mathrm{~cm}$ RMS.

TAO/TRITON data The TOGA-TAO/TRITON observation system was designed to provide continuous, high-quality measurements in the equatorial Pacific waveguide to improve the description, understanding, and prediction of El Niño (McPhaden et al. 1998). The full array consists of approximately 70 moorings in the Tropical Pacific ocean, located between $8^{\circ} \mathrm{N}-$ $8^{\circ} \mathrm{S}$ and $137^{\circ} \mathrm{E}-95^{\circ} \mathrm{W}$, and at depths ranging from 0 to $500 \mathrm{~m}$. They provide, among other things, high-quality measurements of temperature profiles (the accuracy of the data is estimated at $0.1^{\circ} \mathrm{C}$ ). The 1 -day averaged data available on the TAO/TRITON web site were used to assimilate the model. As for the altimetry, each analysis was computed using all the available data gathered within a 5-day interval (2.5 days before and after the analysis time).

In addition, acoustic Doppler current profiler (ADCP) vertical profiles of zonal currents were measured at six specific moorings of the TAO/TRITON array. These moorings are located along the equator at $147^{\circ} \mathrm{E}, 156^{\circ} \mathrm{E}, 165^{\circ} \mathrm{E}, 170^{\circ} \mathrm{W}, 140^{\circ} \mathrm{W}$, and $110^{\circ} \mathrm{W}$. The accuracy of these data is estimated at $5 \mathrm{~cm} \mathrm{~s}^{-1}$. These 
TAO/TRITON moorings provide high-quality and high-frequency independent information for validating the assimilation results at specific mooring locations.

\section{An observed MDT from GRACE gravimetric data}

The most direct and simple method for obtaining the ocean's DT is to compute the difference between the SSH measured from satellite altimetry and a geoid estimate (Fig. 1). However, as already mentioned, the DT is contaminated by large geoid errors. This is especially true for higher harmonics of the order of 20 and more. Alternatively, the temporal mean of the SSH signal, the MSSH, is known with a high level of precision (thanks to the repetitiveness of altimetric missions), and the variable part of the dynamic topography, SLA, can be accurately deduced. The DT can then be deduced by adding the SLA to an estimate of the MDT computed as MDT $=$ MSSH - geoid. However, an accurate estimation of the geoid is still required to evaluate an observed MDT with a sufficient accuracy for combination with the SLA.

In the context of DA, the poor MDT accuracy is usually overcome either by using a numerical model (the model MDT is assumed to be perfect and used as a reference for altimetric residuals) or synthetic solutions based on other data sources (in-situ in general) after sophisticated treatment as mentioned in Section 1. No solution has been found to be adequate. On the one hand, OGCM are subjected to systematic errors resulting from errors in model physics, numerics, inaccurately specified initial conditions, and errors in surface forcing. Those errors result in time-mean circulation discrepancies and then in MDT biases. If an increase of model resolution is able to limit those discrepancies (Smith et al. 2000), typical errors on actual model MDTs (see Barnier et al. 2006) are not compatible with the accuracy required to reference the SLA signal. One the other hand, synthetic solutions (e.g., Mercier 1986; Levitus et al. 1994; Levitus and Boyer 1994; Le Grand et al. 1998; Niiler et al. 2003) are not straightforward to build and often suffer from a lack of resolution. They are based on a set of assumptions that are, in several respects, not sufficiently accurate for our purposes (geostrophic balance, reference level of no motion...). Sometimes, they are based on long-range climatological data (e.g., Levitus et al. 1994; Levitus and Boyer 1994; Le Grand et al. 1998) and suffer from an excessive smoothing for relatively short-term applications. Generally, they also include a significant bias on the reference level that is a critical issue for current and future operational systems. During the last year, the lack of a satisfying MDT to be used to reference altimetric anomalies lead to the development of a number of approaches that blend long-wavelength geodetic data with local oceanographic data to improve upon the purely geodetic MDT at short wavelengths (e.g., Le Grand et al. 2003; Rio and Hernandez 2004; Maximenko and Niiler 2005). Those products are interesting and provide us with fineresolution MDTs. However, the small-scale features of such products still rely on relatively sparse in situ data. Moreover, strong hypotheses are required to infer the MDT from in situ observations. In situ measurements of the total ocean dynamic topography or its corresponding geostrophic circulation are needed, as well as simultaneous altimetric anomalies. It is our concern here to use an absolute altimetric signal deduced solely from geodedic observations and free of any additional assumptions.

Over the past three decades, tracking data from certain satellite constellations have been used to study the Earth's gravity field, leading to substantial improvement in our knowledge of the geoid (Nerem et al. 1995). While these conventional methods have provided accurate information, especially at long wavelengths (Lemoine et al. 1998; Biancale et al. 2000), they are not sufficiently accurate to provide the short wavelengths of the geoid required to evaluate a relevant MDT. This limitation is due to the attenuation of the gravitational signal, the sparse tracking data coverage, and difficulties in modelling the nongravitational forces (Biancale et al. 2000). CHAMP, GRACE, and GOCE are changing this perspective because they have been specifically devised to provide a more accurate geoid. This now offers a reliable alternative to other previous solutions, especially with the recent GRACE products.

\subsection{GRACE gravimetric data}

The geoid used in this study is the EIGEN-GRACE02S geoid from the GFZ in Potsdam (Reigber et al. 2005). This is a medium-wavelength gravity field model based on 110 days of GRACE tracking data. The solution has been derived solely from satellite orbit perturbations and is independent of oceanic and continental surface gravity data. This model, represented by a spherical harmonic expansion, is complete to degree 150 . EIGEN-GRACE02S resolves the large-scale features of the geoid with a great precision reaching an accuracy better than $1 \mathrm{~mm}$ for 1,000 $\mathrm{km}$ half-wavelength. Moreover, EIGEN-GRACE02S represents a substantial improvement regarding the medium-wavelength features of the Earth's gravity field because it resolves the geoid with $1 \mathrm{~cm}$ accuracy down to $275 \mathrm{~km}$ half-wavelength, 
a gain in spatial resolution from 1,000 to $275 \mathrm{~km}$ compared with pre-CHAMP gravity models and from 400 to $275 \mathrm{~km}$ compared with the last CHAMP-only model.

\subsection{The GRACE MDT and the MDT systematic errors}

The so-called GRACE MDT used in this study was computed by the direct method, i.e., by subtracting the EIGEN-GRACE02S geoid from a MSSH estimate. The MSSH used here corresponds to a 7-year mean (1993-1999) based on processed TOPEX/POSEIDON, ERS1\&2, and GEOSAT altimetric satellite data [SMO CLS01, Hernandez et al. (2001)]. To deal with the issue of the noncompatibility of the spectral contents of both surfaces, the difference was developed into spherical harmonics and then truncated to degree 60 (i.e., a resolution of $333 \mathrm{~km}$ ). This spectral approach is known to retain more oceanographic signal than its pointwise equivalent (Bingham et al. 2008). The formal cumulated error of the mean dynamic topography reaches $4 \mathrm{~cm}$ at degree 60 .

In any estimation problem combining information from different sources, one has always to assume that one of the information source is unbiased (this is independent of the method that is used). That information source is needed to serve as a reference to estimate the bias in the other sources of information (if assumed

\section{using the GRACE MDT}
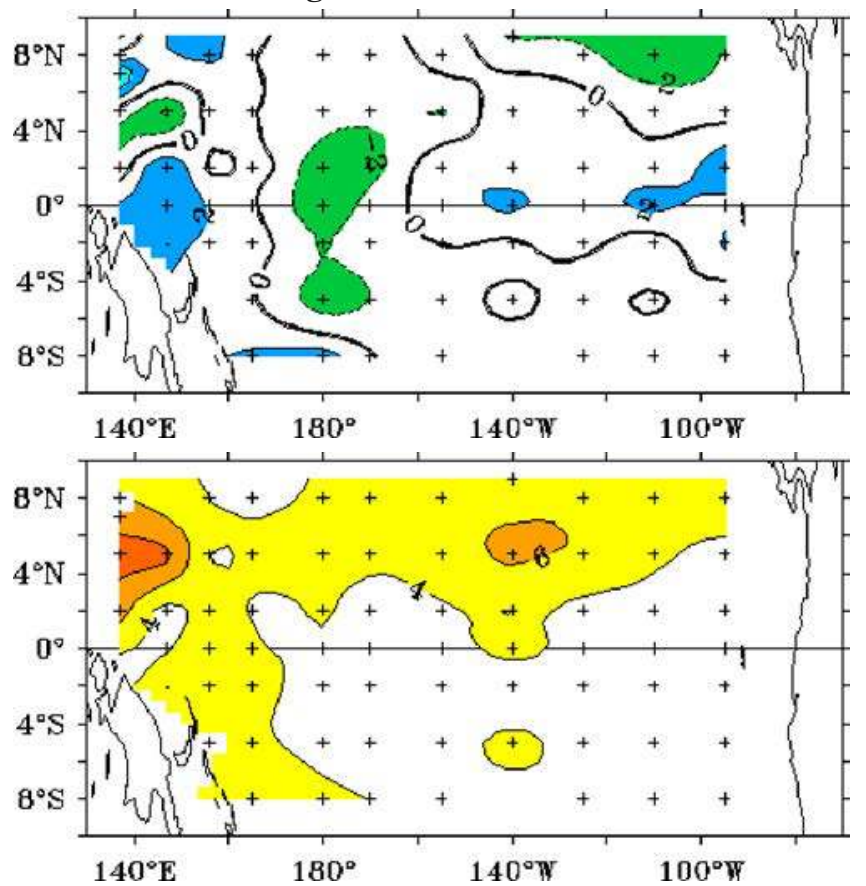

Fig. 2 Mean state difference (top) and RMS difference (bottom) in centimeters for the 1993-2001 period between the 0/500 dbar TAO/TRITON dynamic height and the TOPEX/POSEIDON to exist). In the estimation problem described in this paper, the only possible choice is to assume that the observed MDT is unbiased because the other sources of information (initial condition, model dynamics, TAO arrays) could not serve as references to diagnose a bias in the MDT. In practice, in the assimilation system that we use, the model, and initial condition are also assumed unbiased, and we do not observe very significant systematic differences between model forecast and altimetric observations, but the fact remains that the model and initial condition cannot be used to correct a bias in the MDT. A better possibility would be to try using the TAO profiles to unbias the MDT, but their spatial coverage is too sparse for this to be tempted, also because the bias on the MDT is likely to be mainly a small-scale bias. Hence, in our experiments, any bias in the observed MDT contaminates the results, without any possibility of detecting it, until a better source of information is available. A consequence of this bias will be analyzed at the end of Section 4.

\subsection{Assessment in the tropical pacific}

We found it useful to perform a first assessment of the GRACE Tropical Pacific MDT by reference to dynamic heights computed from in-situ observations. The $70 \mathrm{TAO} / \mathrm{TRITON}$ moorings provide in situ
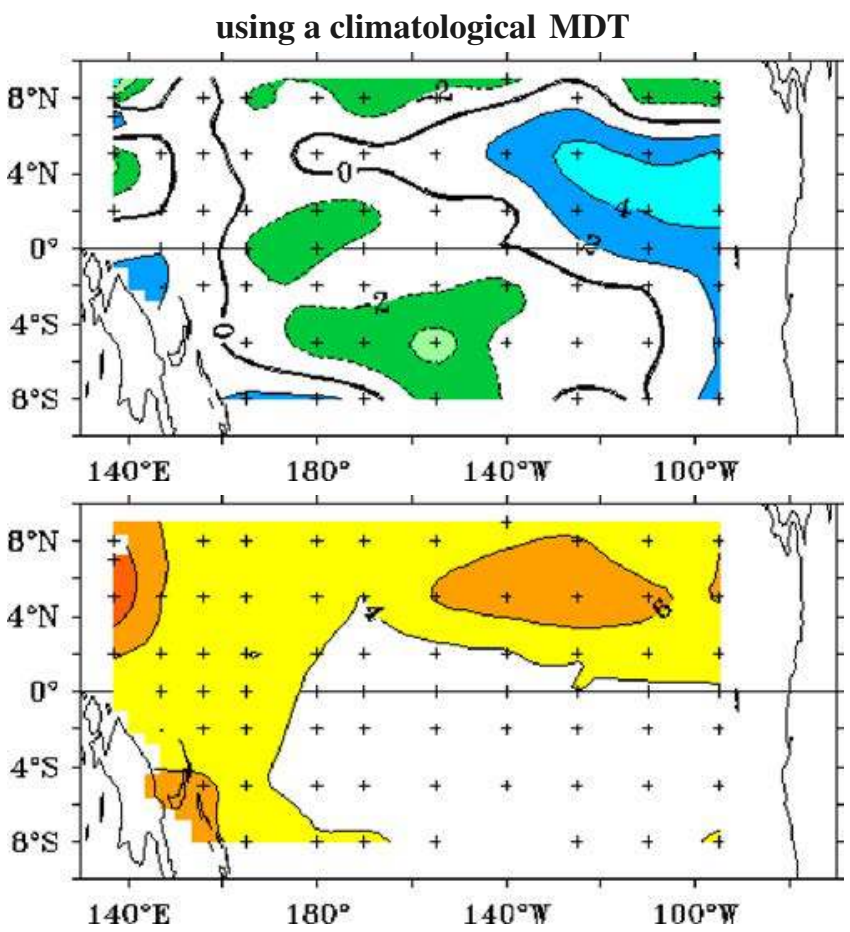

sea level using as reference the GRACE MDT (left) or the Levitus climatological MDT (right). Locations of TAO/TRITON moorings are shown by crosses 
observations of the 0/500 dbar dynamic height in the tropical wave guide with a global, large-scale coverage. The TAO/TRITON dynamic heights are computed using the in-situ TAO/TRITON temperature profiles and an estimation of the salinity along the upper water column down to 500 dbar from a local T-S relation computed from climatological data. The dynamic height calculation validity is then limited by the extent of the reference level chosen and by use of a statistical estimation of salinity, which results in an overall error of about $2-3 \mathrm{~cm}$ for the entire TAO/TRITON array. To get an absolute sea level, the TOPEX/POSEIDON sea level anomalies were added both to the GRACE MDT and to a climatological MDT estimated from the mean dynamic height field referenced to 1,500 dbar deduced from the Levitus climatology. Sea levels were mapped onto a $1^{\circ} \times 1^{\circ}$ grid and sampled every 5 days over the 1993-2001 period so that they could be compared with the TAO/TRITON dynamic heights.

The mean state difference (Fig. 2) between the sea level and the TAO/TRITON dynamic height is $2.4 \mathrm{~cm}$ when the Levitus MDT is considered and $1.95 \mathrm{~cm}$ when the GRACE MDT is considered. The GRACE MDT and the climatology MDT differ mainly in the eastern side of the basin and in the central South Pacific. The RMS difference (Fig. 2), which incorporates the difference in terms of means and variability, is $4.6 \mathrm{~cm}$ when the Levitus MDT is considered and $4.3 \mathrm{~cm}$ when the GRACE MDT is considered. Most of these differences are concentrated in the northern hemisphere in a strong shear area between the South Equatorial Current (SEC) and the North Equatorial Counter Current (NECC). The dynamic topography referenced with GRACE MDT fits the real Tropical Pacific Ocean level reasonably well and represents a clear improvement with regard to climatology and, more particularly, to earlier results using CHAMP gravimetric data (Gourdeau et al. 2003).

\subsection{Complementarity of altimetric and in situ data}

The use of an observed and realistic MDT, instead of the MDT simulated by the free model, provides greater compatibility between altimetric observations and in situ observations like the TAO/TRITON temperature profiles (Castruccio et al. 2006). This was a real issue with prior approximate MDTs, which uncertainties actually translate into incompatibilities between in situ and satellite observations (P03; Castruccio et al. 2006).

In this work, to assess the compatibility between the two assimilated sets of observations, i.e., the altimetric SLA referenced with the GRACE MDT and the TAO/TRITON temperature profiles, a first series of short experiments has been conducted for the year 1993 using the assimilation system described earlier. One reference experiment is the free run (EXP0). Three
Fig. 3 Absolute dynamic topography (top panel, in meters) and temperature (bottom panel, in degrees Celsius) RMSD for the year 1993 with respect to observations over the Tropical Pacific. Plots show EXP0 (green), EXP1 (blue), EXP2 (red), and EXP3 (black)
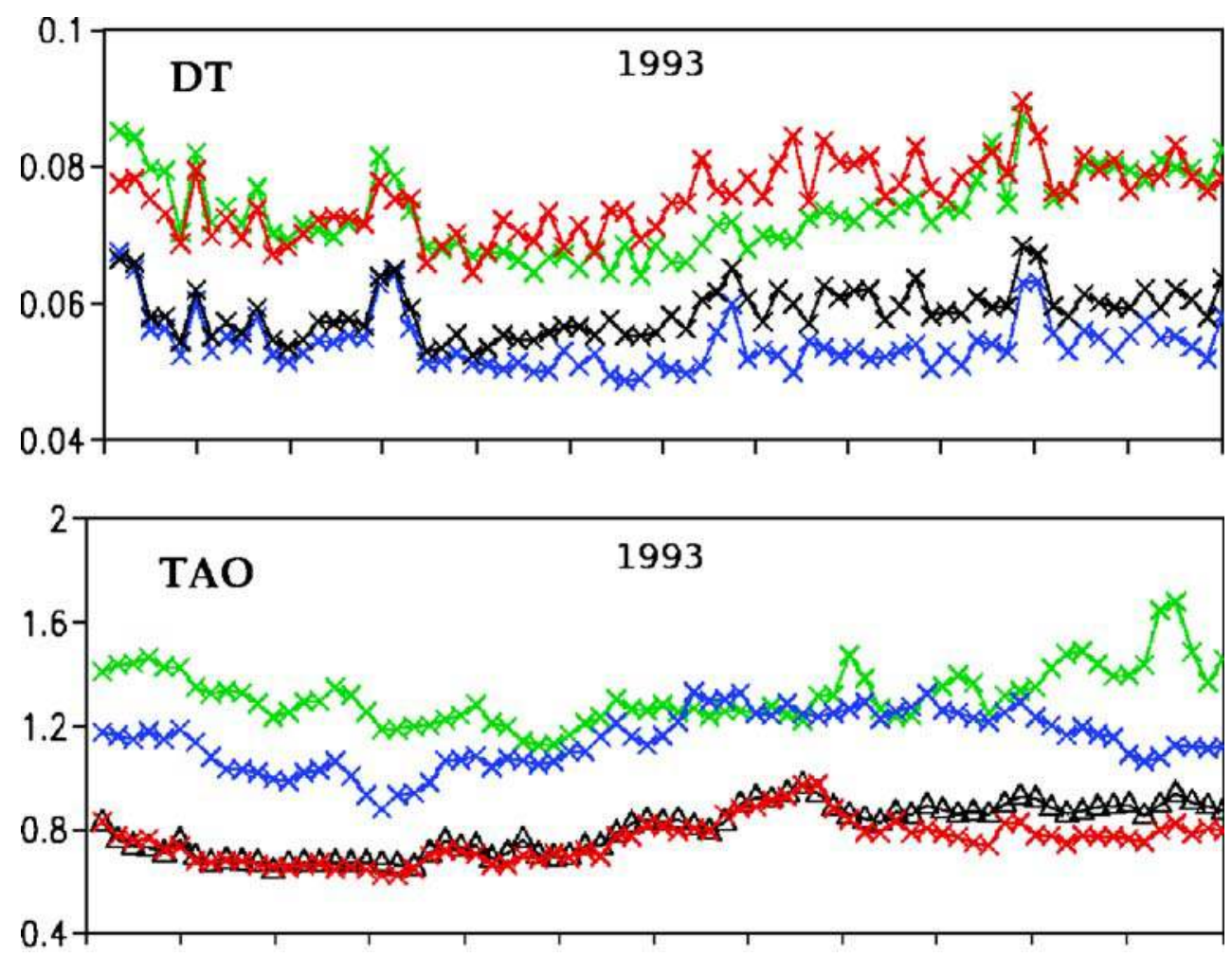
experiments are conducted with DA, exactly with the same protocol except for the data used. In experiment EXP1, only altimetry observations are used. In experiment EXP2, TAO/TRITON temperature profiles are only used. In experiment EXP3, altimetric and TAO/TRITON observations are jointly considered.

Figure 3 shows the changes in RMS difference (RMSD) for the different simulations. A slight deterioration may be observed in RMSD with respect to the observed dynamic topography when going from a altimetry alone assimilation (EXP1, in blue) to a altimetry + TAO/TRITON assimilation (EXP3, in black), increasing from 5.5 to $6.0 \mathrm{~cm}$. As we saw previously, there are some residual differences between the TAO/TRITON dynamic heights and the altimetric measurements. It is therefore not surprising that the joint assimilation of these two sets of data reveals in a slight deterioration of results. The improvement, however, is significant in relation to the free simulation (green) and the simulation assimilating only the TAO/TRITON observations (red), with a mean RMSD with respect to the observed DT of $7.5 \mathrm{~cm}$ for both these experiments. In brief, joint assimilation (EXP3) does not significantly degrade the results on dynamic topography data compared to pure dynamic topography data assimilation (EXP1). A significant improvement may also be noted in terms of RMSD with respect to the TAO/TRITON data. The mean RMSD decreases from $1.32^{\circ} \mathrm{C}$ for the free simulation to $1.15,0.76$, and $0.80^{\circ} \mathrm{C}$, respectively, for experiments EXP1, EXP2, and EXP3. In brief, joint assimilation (EXP3) does not degrade the results on temperature data compared to pure temperature data assimilation (EXP2).

Therefore, these preliminary results confirm the good compatibility between altimetry and TAO/ TRITON in-situ temperature data assimilated in the above conditions. They also represent a clear improvement over the results of earlier studies not using an observed MDT deduced from geodetic data, and in particular, those of $\mathrm{PO3}$.

\section{Hindcast experiment (1993-1998)}

Two simulations were performed for the 1993-1998 period, a period encompassing the likely strongest El Niño/La Niña event of the 20th century. The first simulation (FREE) is a free run without DA. The second simulation (ASSIM) includes assimilation of altimetric data referenced with the GRACE MDT and in situ TAO/TRITON temperature profiles. The same initial condition and the same forcing scheme are used. FREE
Fig. 4 Absolute dynamic topography (top panel, in meters) and temperature (bottom panel, in degrees Celsius) RMSD over the 1993-1998 period with respect to assimilated observations over the Tropical Pacific. FREE (green) and ASSIM (black) are plotted
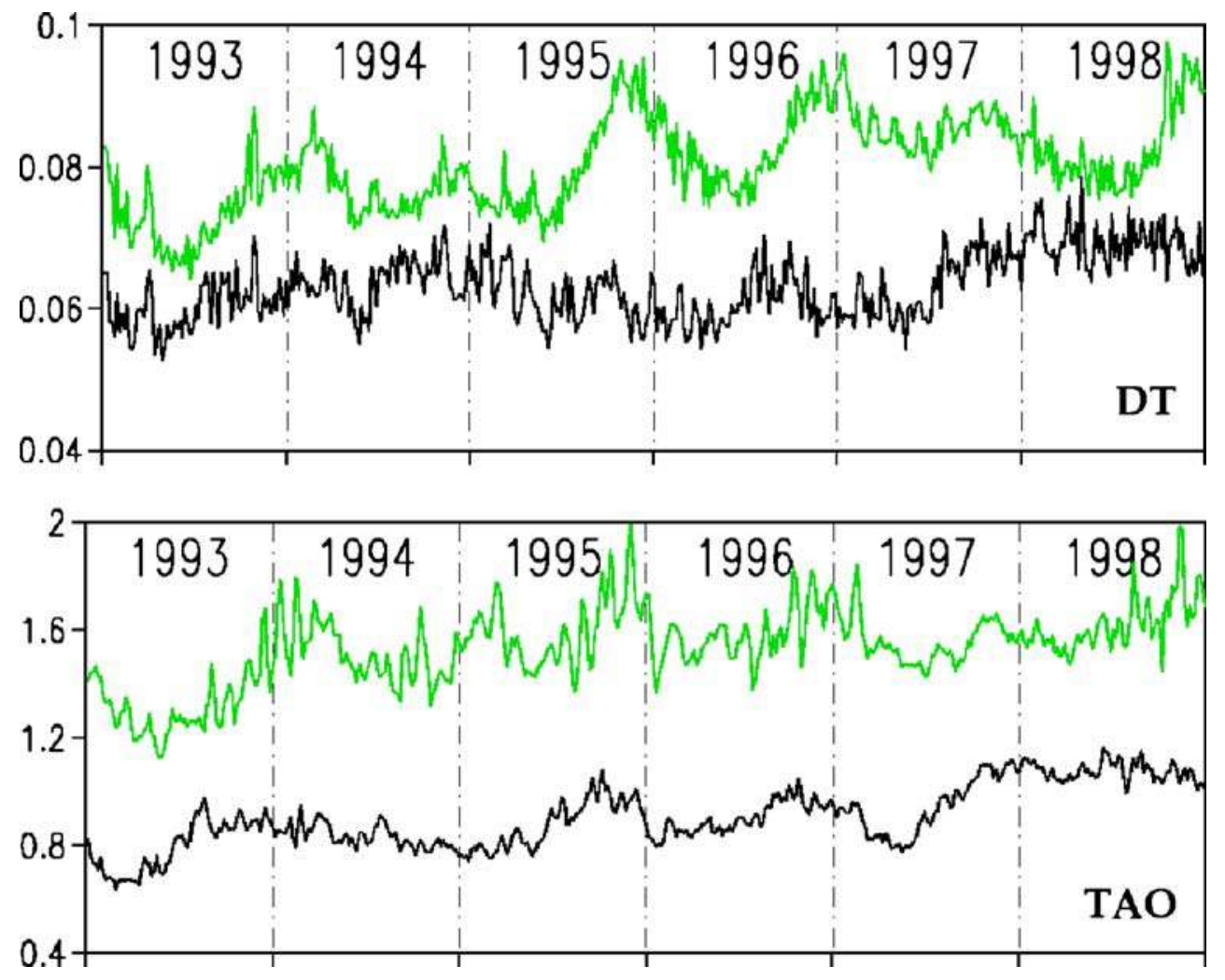
(respectively ASSIM) is similar to experiment EXP0 (respectively EXP3) introduced previously except that it extends over the 1993-1998 pluri-annual period.

\subsection{Model-observation misfit}

The RMSD between the assimilated data and both FREE and ASSIM is shown in Fig. 4. The free simulation error on the dynamic topography averages $8.1 \mathrm{~cm}$ over the 6 years. The assimilation enables a reduction of this error down to $6.3 \mathrm{~cm}$ on average over the period 1993-1998. A slight increase may be noted in the RMSD in FREE over the 6 years of simulation on which several seasonal maximums are superimposed in boreal winter. On the other hand, the RMSD is stable for ASSIM, even if there is a slight increase during the El Niño/La Niña period of 1997-1998.

Compared with the TAO/TRITON temperature data, the mean RMSD decreases by $1.54^{\circ} \mathrm{C}$ for FREE and by $0.9^{\circ} \mathrm{C}$ for ASSIM. The change in the RMSD over the period 1993-1998 for the free simulation is

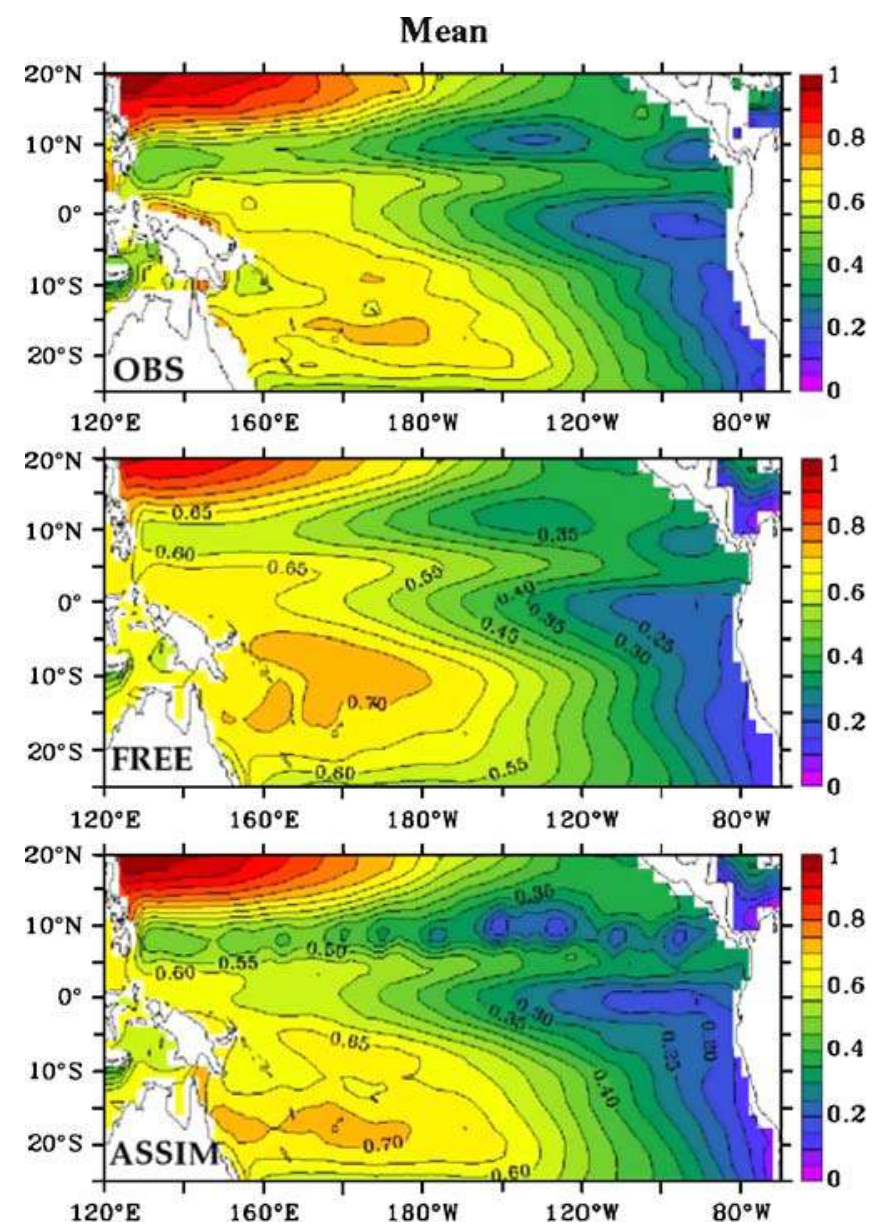

less obvious. The maximum values are also less marked, though they are still present. In addition, they are well correlated with the maximum values of the RMSD with respect to the observed dynamic topography. A slight increase in the RMSD may also be noted during the El Niño/La Niña period.

Dynamic topography One of the aims of using an observed MDT such as the GRACE MDT is to control the mean structure of the model together with its variability. Figure 5 presents the maps of the MDT for the period 1993-1998, as well as the standard deviation of its variability, for the altimetric observations, FREE and ASSIM. The MDT structures simulated with ASSIM are in much better agreement with observed MDT structures, particularly in the region of the Central Southern Tropical Pacific, where the MDT is more realistic and differs quite clearly from the FREE MDT. The representation of the ridge associated with the North Equatorial Counter Current (NECC) is also significantly improved in ASSIM, with much steeper meridional gradients, which is in agreement with the

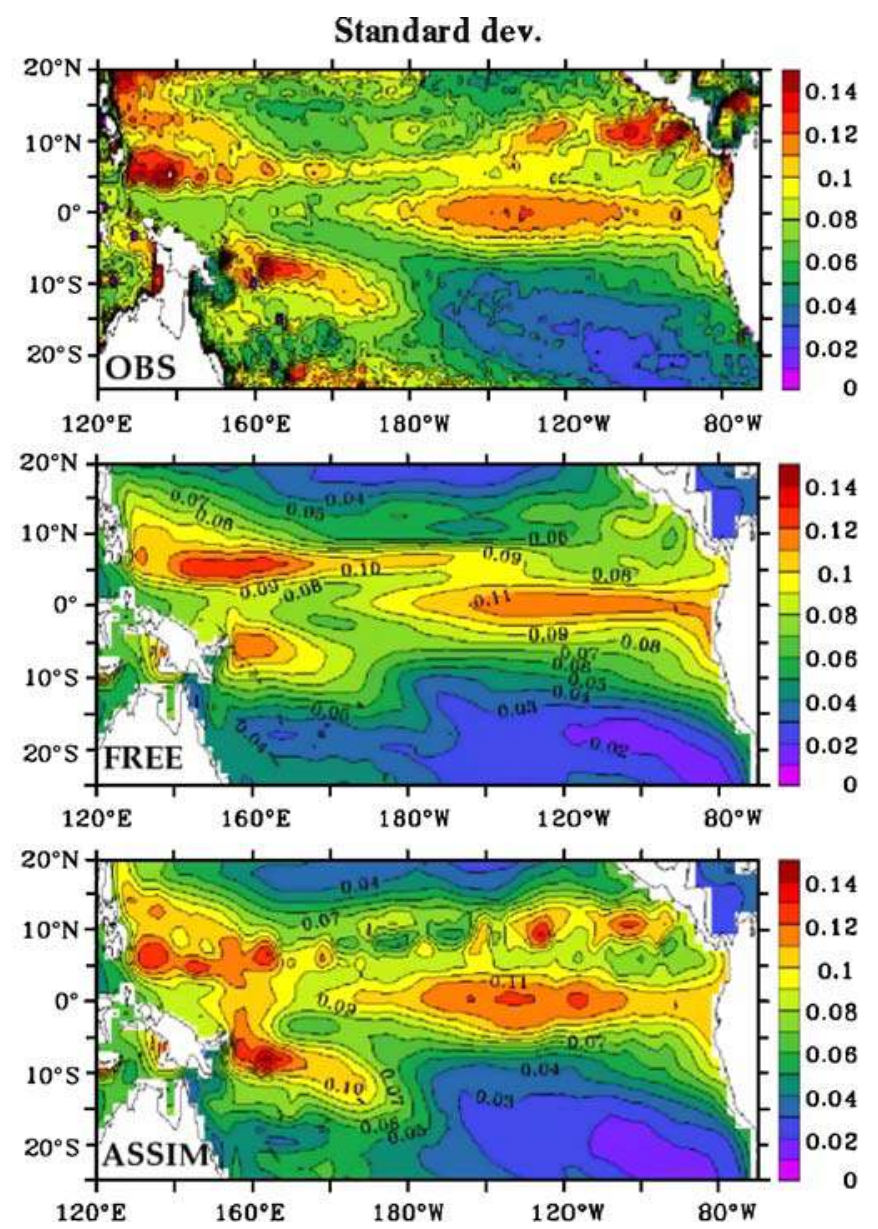

Fig. 5 Mean dynamic topography (in meters, left) and standard deviation of the dynamic topography (in meters, right) for the 19931998 period obtained from observations (top panels), from FREE (middle panels) and from ASSIM (bottom panels) 
observations. Still in the region of the ridge, around $10^{\circ} \mathrm{N}$, the ASSIM MDT shows small structures that are not very realistic for an average based on a 6-year period. This type of structure is absent both in the observations and in FREE. We also saw in Section 3 that the largest errors between the dynamic height obtained from TAO/TRITON moorings and the dynamic topography observed by satellite are seen in this region. We will come back to this point at the end of the section.
With regard to observed variability, it is dominated by the strong El-Niño of 1997, with a marked maximum of variability centered on the equator in the east of the basin. This maximum corresponds to the signature of Kelvin waves (Dewitte et al. 2003) that deepen the thermocline and propagate from west to east, thereby contributing to the advection of the warm waters of the Western Pacific towards the east of the basin during the growing phase of the phenomenon. FREE also provides a very satisfactory representation of sea level
Fig. 6 Section showing standard deviation of temperature in degrees Celsius along the equator during 1993-1998 period obtained from

TAO/TRITON network observations (top panel), FREE (middle panel), and ASSIM (bottom panel). The black lines show isotherm mean depths for each data set

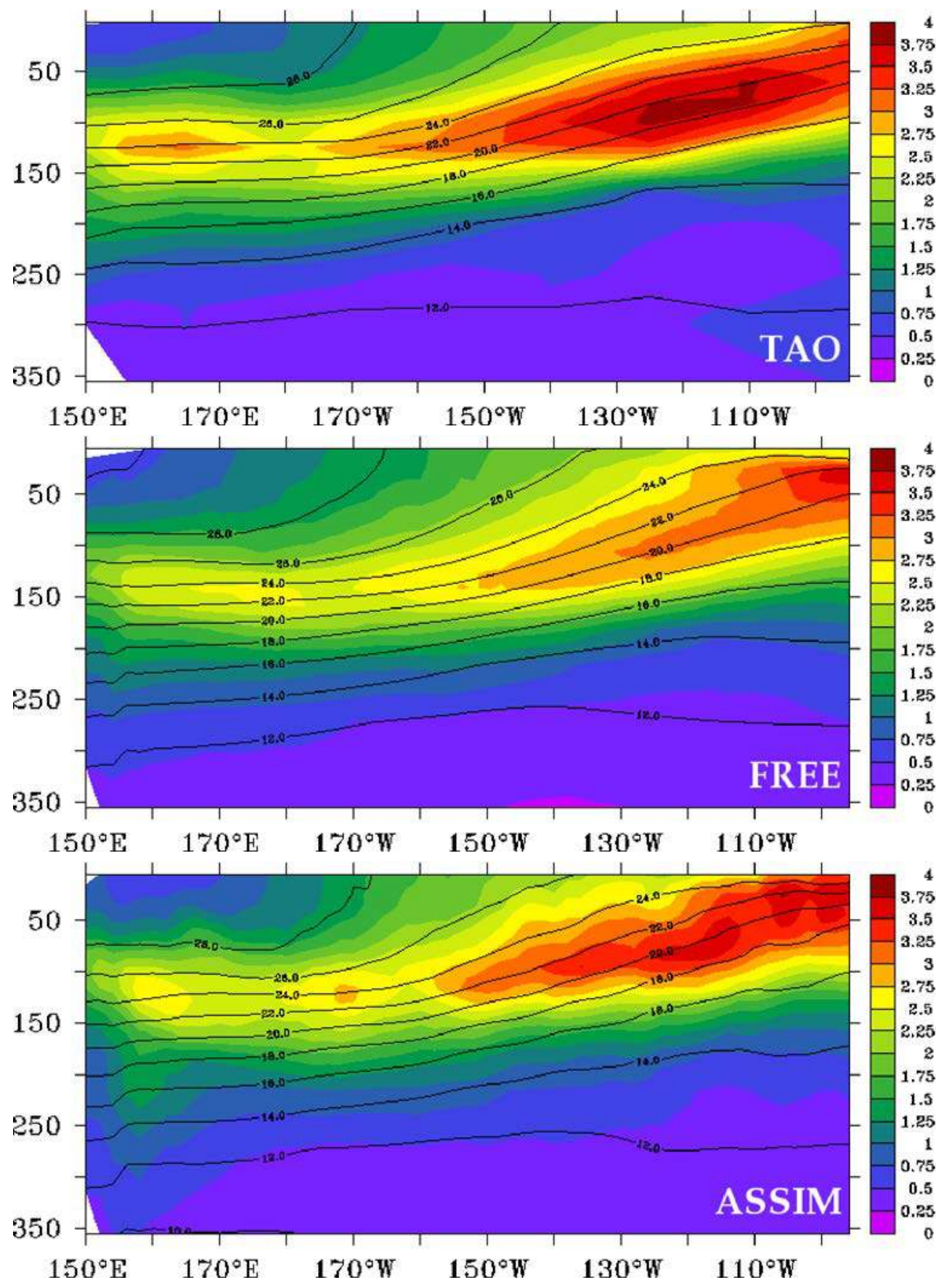


variability. The maximum of variability at the equator is clearly present, even if it is a little underestimated. ASSIM is able to efficiently strengthen this variability maximum and to reposition it more in the centre of the basin, which is more in agreement with the observations. In FREE, the maximum of variability at the equator extends as far as the American coast, reflecting an overestimation of seasonal variability in the "cold tongue" region. This error is well corrected by assimilation. Another positive point of assimilation is the strengthening of variability in the east, at $10^{\circ} \mathrm{N}$, associated with strong Ekman pumping (Kessler 1990) in this region. In the west, assimilation decreased the zonal extension of the maximum of variability associated with the propagation of Rossby waves along latitude $5^{\circ} \mathrm{N}$, which is in agreement with observations. Variability simulated with ASSIM in the Tropical South Pacific is also generally more realistic, with a region of very limited variability in the southeast and one of more marked variability in the southwest. On the other hand, a negative aspect of ASSIM is the exaggerated variability at the equator in the west of the basin, around longitude $160^{\circ} \mathrm{E}$.

Temperature Figure 6 shows the standard deviations of the temperature field for a section at the equator. The mean depths of the isotherms are superimposed. Assimilation has a strong and beneficial impact on the mean vertical structure and the variability of the temperature field. Variability at the level of the thermocline is strengthened in ASSIM, particularly in the west of the basin. However, compared with observations, it remains underestimated. This strengthening of variability in the temperature field is accompanied by a marked modification of the mean depth of the isotherms. In FREE, the isotherms are systematically too deep (by about $20 \mathrm{~m}$ ) compared with observations. This error is well corrected with ASSIM. It may be noted in particular that the $16^{\circ} \mathrm{C}$ level at the basis of the thermocline is significantly shoaled in the east of the basin, in agreement with observations.

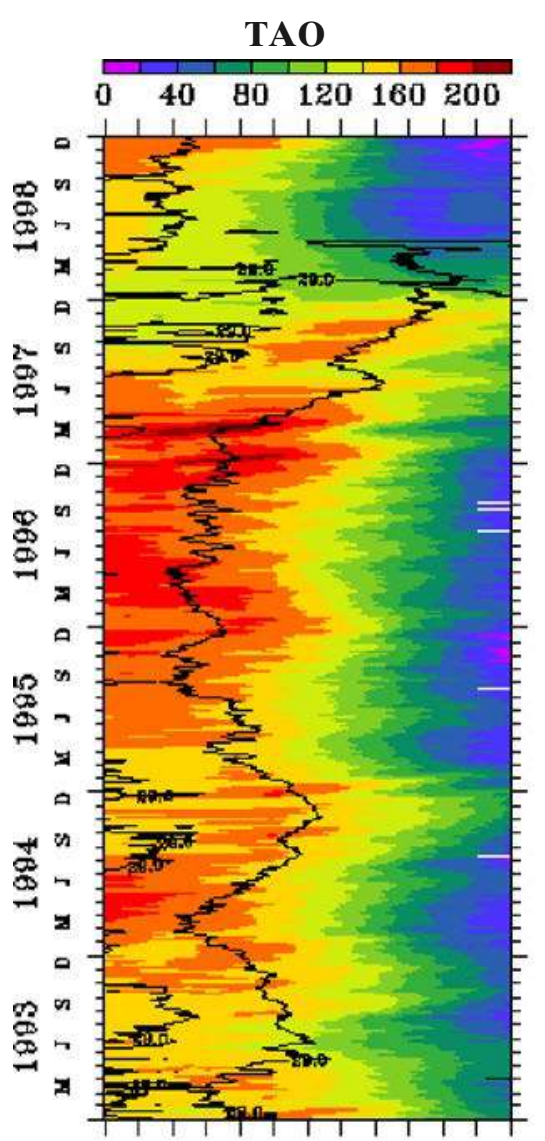

$140^{\circ} \mathrm{E} 170^{\circ} \mathrm{E} 160^{\circ} \mathrm{Y} 150^{\circ} \mathrm{T} 100^{\circ}$ \%

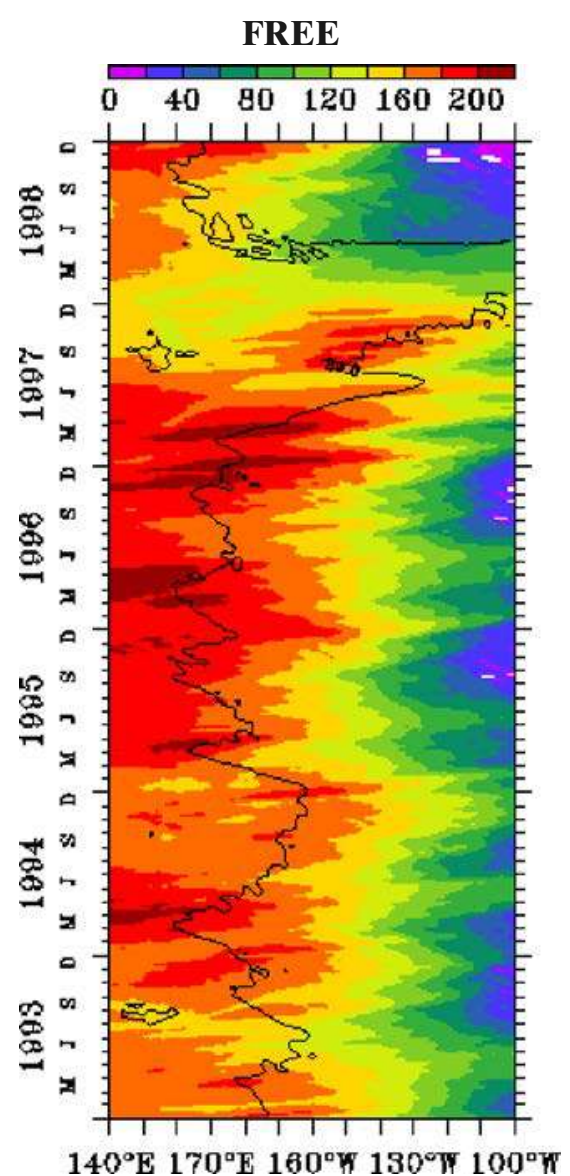

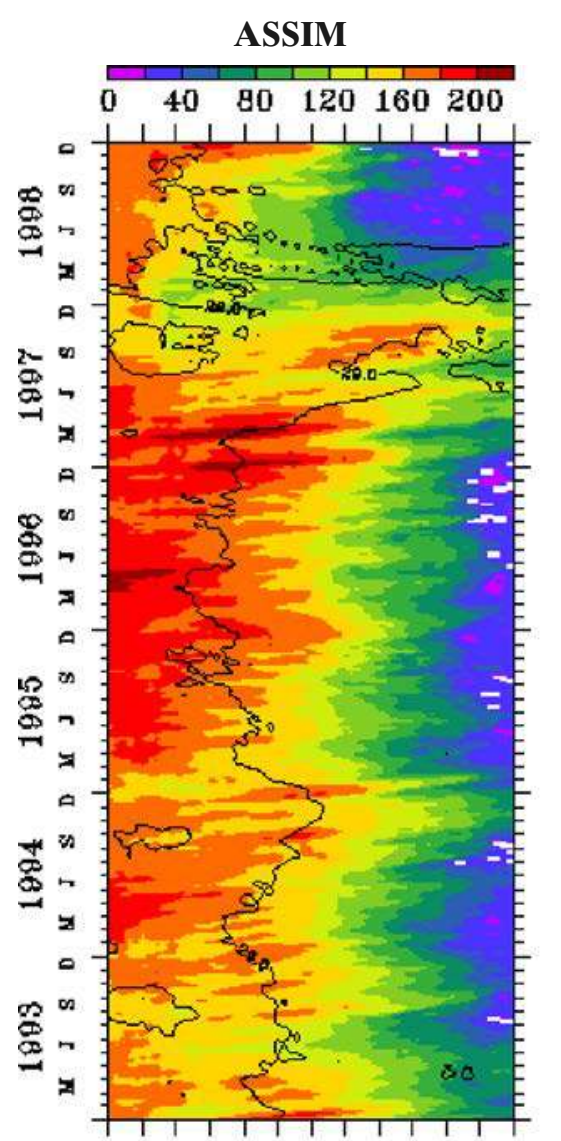

$140^{\circ} \mathrm{E} 170^{\circ} \mathrm{E} 160^{\circ} \mathrm{W} 130^{\circ} \mathrm{W} 100^{\circ} \mathrm{W}$

Fig. 7 Time-longitude diagram of $20^{\circ} \mathrm{C}$ isotherm depth (ISO20) averaged between $2^{\circ} \mathrm{N}$ and $2^{\circ} \mathrm{S}$ based on the TAO/TRITON observations (left panel), FREE (middle panel), and ASSIM (right panel). Superimposed on each panel is the $29^{\circ} \mathrm{C}$ isotherm 
Depth of $20^{\circ} \mathrm{C}$ isotherm The depth of the $20^{\circ} \mathrm{C}$ isotherm is a good proxy of the depth of the thermocline in the Tropical Pacific. To appreciate the impact of data assimilation on the depth of the thermocline during the period 1993-1998, we plotted (Fig. 7) the changes in the mean depth of the $20^{\circ} \mathrm{C}$ isotherm averaged between $2^{\circ} \mathrm{S}$ and $2^{\circ} \mathrm{N}$ for the observations of the TAO/TRITON network (left) and for ASSIM (right) and FREE (centre). The first thing that should be pointed out is the quality of the free simulation. Most of the structures are present. Thus, the signature of the $1994 \mathrm{El}$ Niño on the depth of the $20^{\circ} \mathrm{C}$ isotherm may be noted, with a deepening of the thermocline in the east of the basin. Also visible, and even more marked, is the $1997 \mathrm{El} \mathrm{Niño,} \mathrm{which} \mathrm{reflects} \mathrm{in} \mathrm{a} \mathrm{flattening} \mathrm{of}$ the thermocline over the whole width of the basin. Finally, the signature of the two Kelvin waves that were particularly intense at the beginning of the 1997-1998 El Niño (in January 1997 and again in February/March of the same year) may also be noted. These two waves
Fig. 8 Mean zonal velocity (in meters per second) at 15 -meter depth according to the Niiler (2001) climatology (top panel) and the mean for the 1993-1998 period obtained from FREE (middle panel) and from ASSIM (bottom panel)

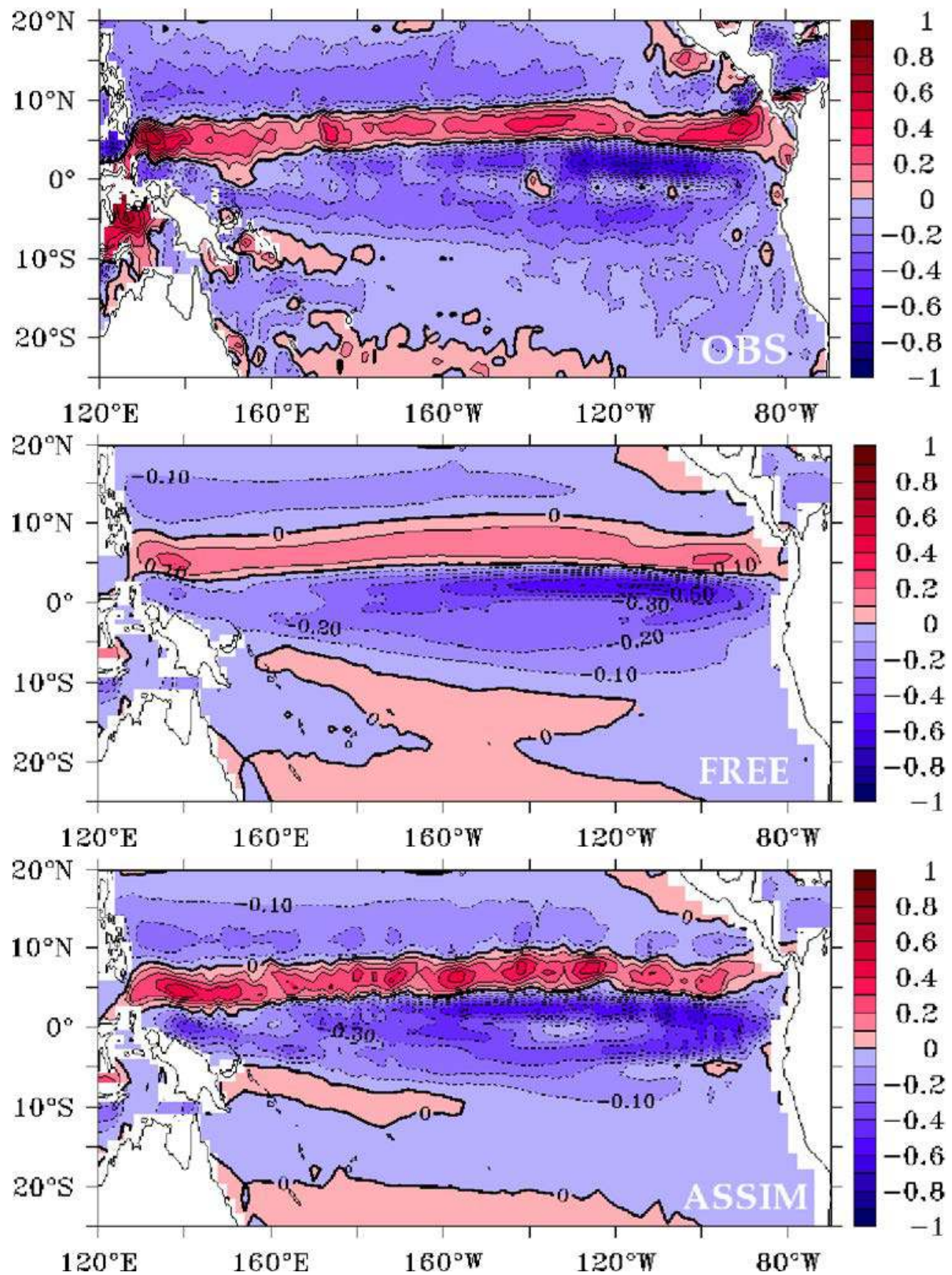


probably played an important role in the onset of the El Niño in 1997-1998 (Lengaigne et al. 2002), particularly the Kelvin wave generated following the anomalous westerly winds event (WWE) of February/March, which displaced the warm pool eastward and efficiently deepened the thermocline across the whole width of the basin. The quality of the ERS + TAO/TRITON winds is probably a significant factor of this good free model ability. Data assimilation enables an even more realistic simulation. The $20^{\circ} \mathrm{C}$ isotherm is systematically too deep in FREE (see also Fig. 6). This error is corrected in ASSIM, likely thanks to TAO/TRITON data, which allows readjusting the depth of the $20^{\circ} \mathrm{C}$ isotherm to the depth observed by the TAO/TRITON network. Seasonal variability in the depth of the thermocline is overestimated by FREE in the east of the basin. The thermocline is too deep in summer/autumn when the southeast trade winds are at their strongest and equatorial upwelling, as a result, is most marked. This is in agreement with the overestimation of the variability in dynamic topography observed in Fig. 5. ASSIM exhibits a more realistic level of variability in this region. For 1998, when La Niña conditions were prevailing, ASSIM is able to correct the depth of the thermocline, as this is too deep in the free run, particularly in the Central Pacific.
Fig. 9 Mean zonal velocity profiles (in meters per second) along the equator at $165^{\circ} \mathrm{E}, 170^{\circ} \mathrm{W}, 140^{\circ} \mathrm{W}$, and $110^{\circ} \mathrm{W}$, respectively, from left to right and from top to bottom. Each panel shows the mean current for the 1993-1998 period obtained from TAO/TRITON ADCP (pink crosses), from FREE (green line) and from ASSIM (black line)
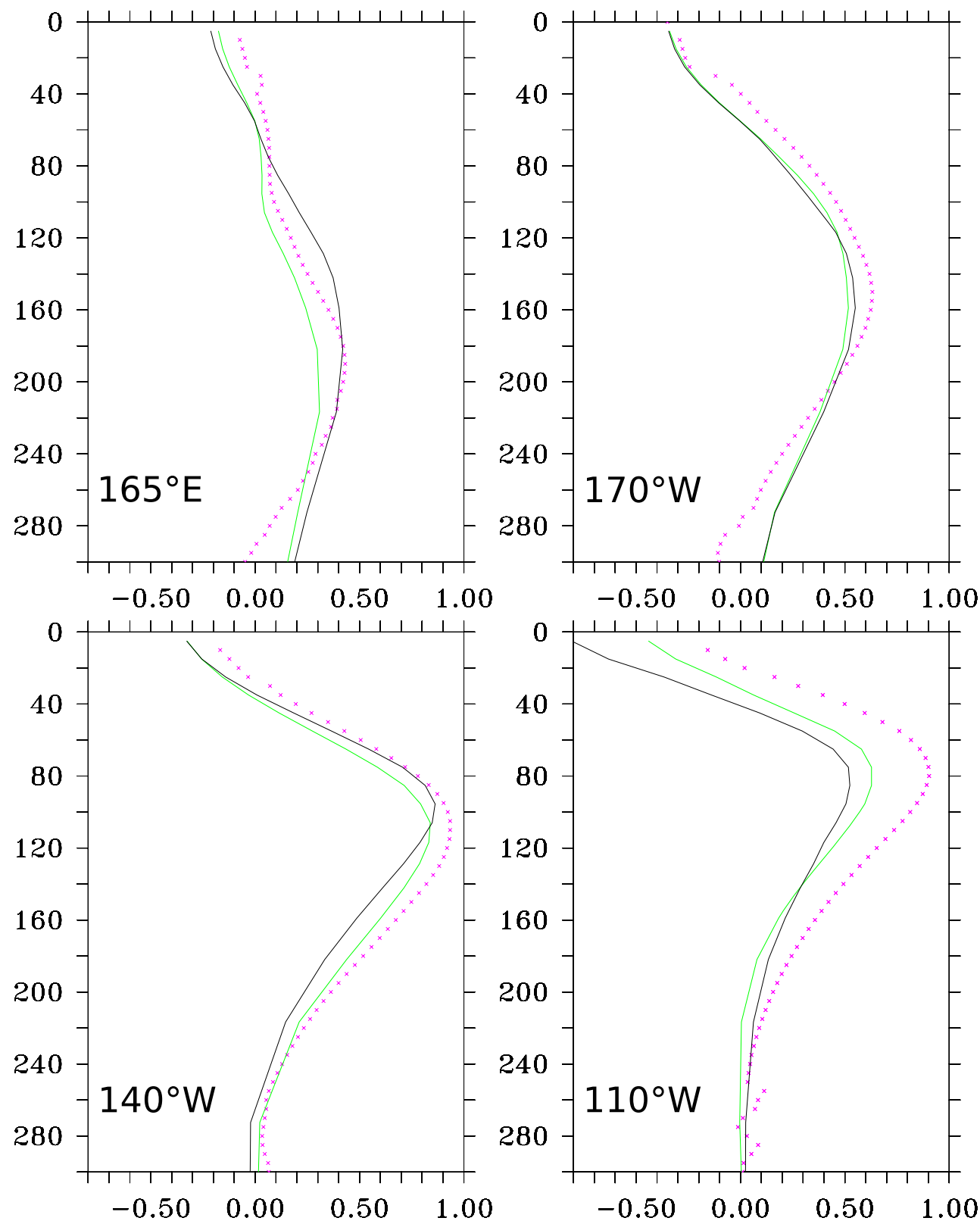


\subsection{Validation with independent data}

Surface currents The examination of surface currents is particularly revealing in the tropical regions where currents become more sensitive to the meridional gradients of the dynamic topography as the Coriolis force disappears at the equator. The map of mean zonal currents at $15 \mathrm{~m}$ depth for the observations, FREE, and ASSIM are provided in Fig. 8. The observations come from the surface current climatology proposed by Niiler (2001). This climatology was obtained by satellites following the path of SVP drifting buoys used within the framework of the international WOCE programme. ASSIM currents are much more realistic than those obtained in FREE. The NECC has been significantly intensified, which is in agreement with the Niiler (2001) climatology. The South Equatorial Current (SEC) is also more intense. The separation of the SEC into two branches, north and south branches, can be clearly observed in the centre of the Tropical Pacific, contrary to FREE. This misrepresentation of the two SEC branches is one of the known issues of the ORCA2 simulation (Lengaigne et al. 2003). On the other hand, this separation is only poorly represented in ASSIM in the extreme east of the basin, reflected in exaggerated surface velocities at the equator. In the north, the North Equatorial Current (NEC) reaches speeds of more than $20 \mathrm{~cm} \mathrm{~s}^{-1}$ which is still a little too weak compared with the climatology deduced from the SVP drifting buoys but nevertheless represents a clear improvement over FREE. In the southern hemisphere, ASSIM provides significantly more realistic surface currents with a South
Equatorial Counter Current (SECC) that remains well confined to the west of the basin, beyond $180^{\circ}$. The currents towards the east associated with the return branch of the southern subtropical gyre are only present to the south of $20^{\circ} \mathrm{S}$, as in the climatology.

Subsurface currents To quantify the impact of assimilation on the zonal currents at depth, we evaluated our simulation with the help of currents measured by the ADCP fitted on certain TAO/TRITON moorings along the equator (as indicated in Section 2). The mean profiles of the zonal currents are calculated for the period 1993-1998, and comparisons are made for longitudes $165^{\circ} \mathrm{E}, 170^{\circ} \mathrm{W}, 140^{\circ} \mathrm{W}$, and $110^{\circ} \mathrm{W}$, these being the only points fitted with ADCP sensors and providing data in a virtually continuous manner over the entire study period. First of all, it may be observed in Fig. 9 that the vertical structure of the currents at the equator is realistic, whether or not data are assimilated in the free model. The intensity at the heart of the Equatorial Under Current (EUC) simulated in free mode is systematically a little underestimated. Data assimilation helps limit this error. In particular, the start of the EUC in the west of the basin is improved and the velocities simulated with ASSIM are comparable to in situ current observations. In the east, on the other hand, for the $110^{\circ} \mathrm{W}$ profile, assimilation has a negative impact with a slight decrease in intensity at the heart of the EUC, which was already too weak in FREE. At this location, assimilation deteriorates of the representation of the currents above the heart of the EUC, with surface speeds towards the west that are
Fig. 10 Horizontal distributions of XBT profiles available for the 6 years of the assimilation experiment. Superimposed in red are the three selected routes corresponding to the Tokyo-Auckland, San Francisco-Auckland, and Panama-Auckland maritime lanes

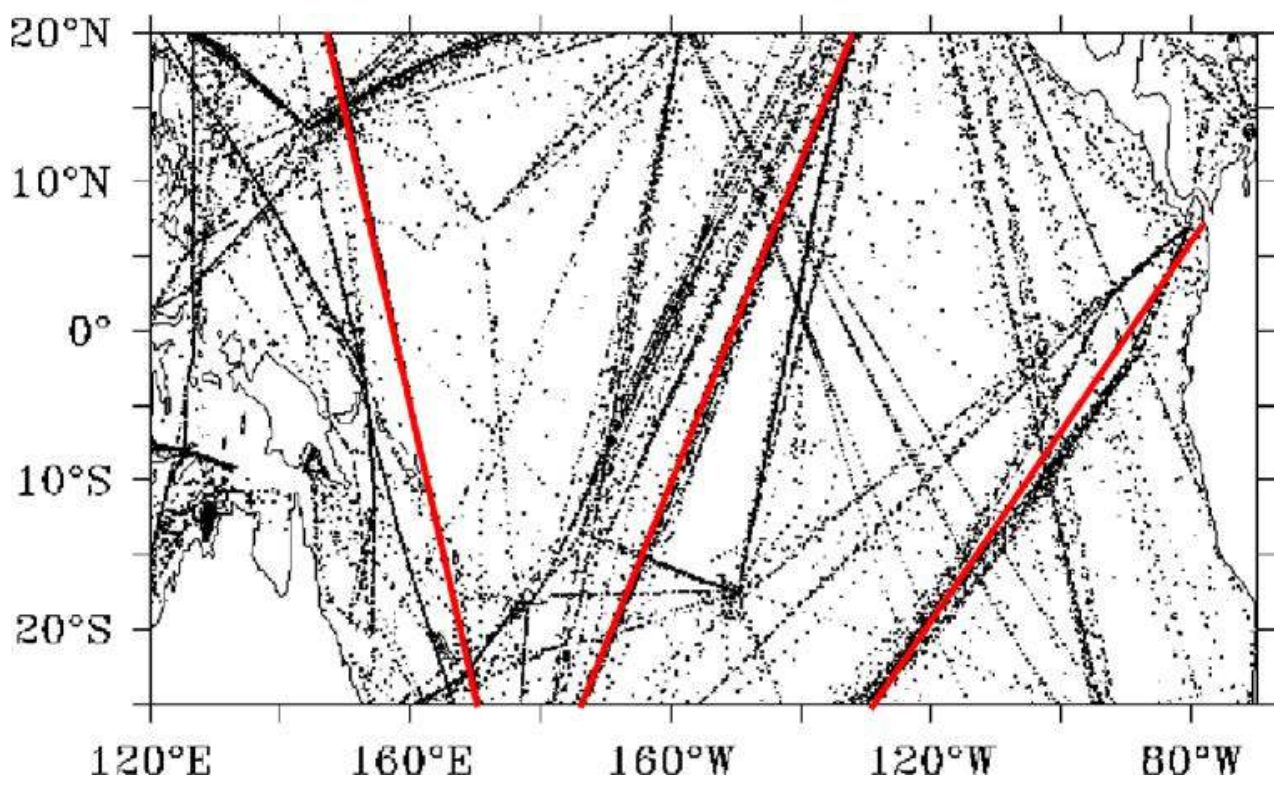


far greater than TAO/TRITON observations and even greater than the free run velocities.

Expendable bathythermograph The expendable bathythermograph (XBT) vertical temperature profiles represent another useful and independent source of information for validation. The data used here were obtained through the site of the CORIOLIS project (http://www.coriolis.eu.org). About 60,000 profiles are available for the 1993-1998 period, covering our entire study area. The position of these profiles is shown in Fig. 10. XBT data have a very irregular spatial
FREE
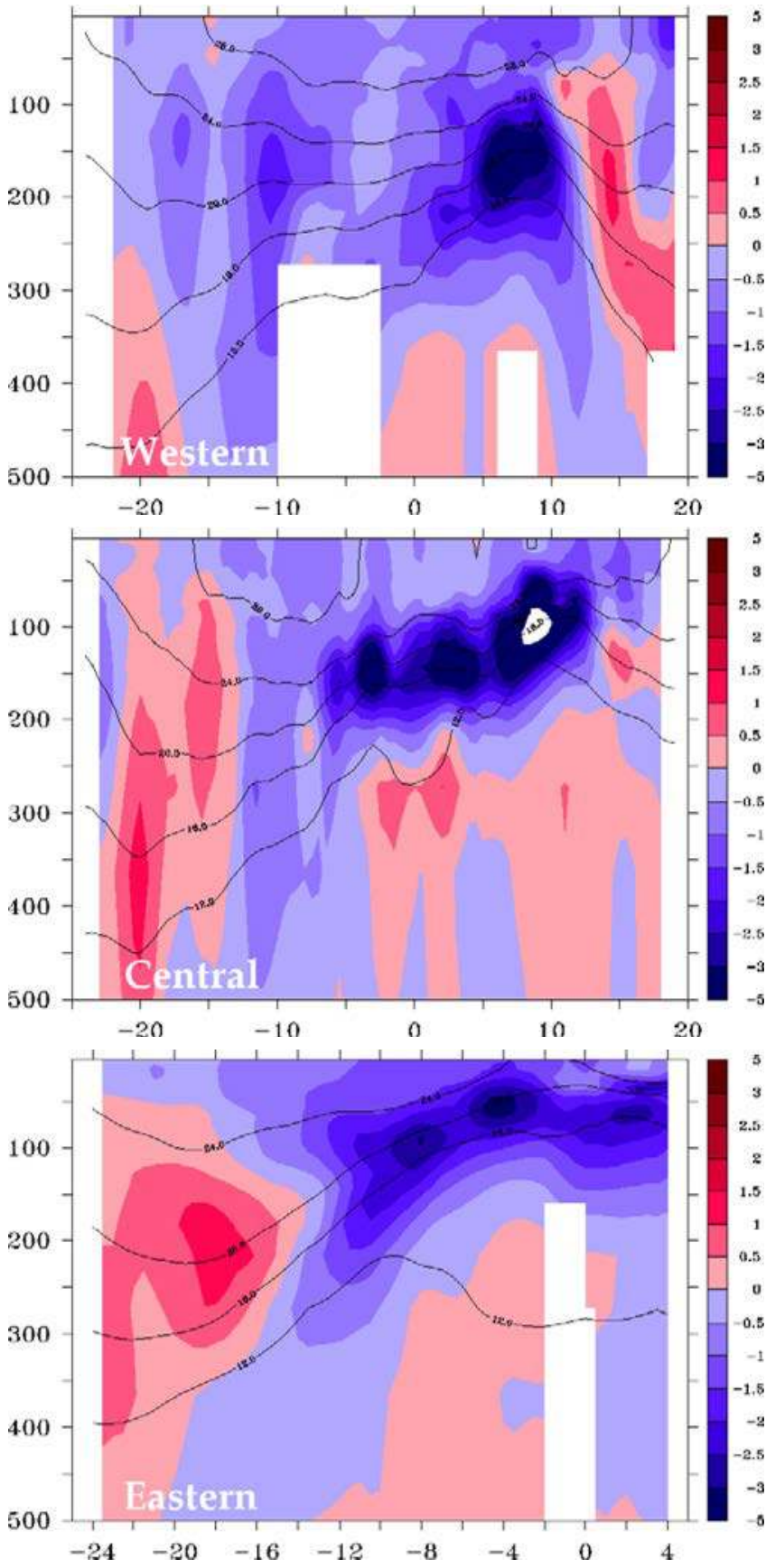

Fig. 11 Differences between the XBT mean temperature section (in degrees Celsius) over the 1993-1998 period along the Western (top panels), Central (middle panels) and Eastern (bottom panels) Pacific lanes and the mean temperature section simulated in
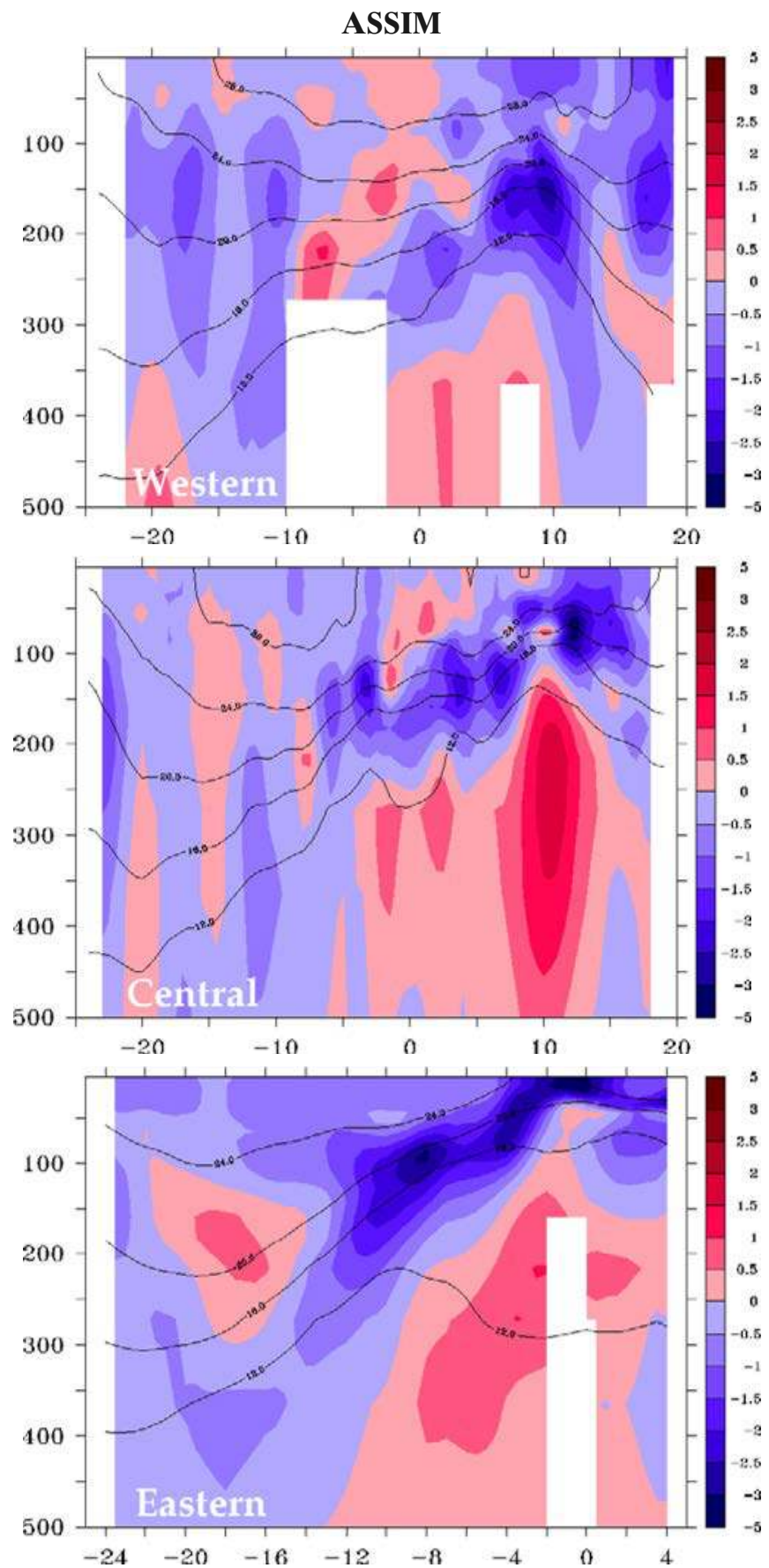

FREE (left) and in ASSIM (right). The black lines correspond to the mean depth of the $12-16-20-24$ and $28^{\circ} \mathrm{C}$ isotherms over the 1993-1998 period obtained from XBT data 
and temporal coverage. To evaluate mean vertical temperature sections that are really representative of the mean situation in the Tropical Pacific, we extracted three lanes that were particularly well sampled (in red in Fig. 10), positioned, respectively, in the Western Pacific (Tokyo-Auckland), the Central Pacific (San Francisco-Auckland), and the Eastern Pacific (Panama-Auckland).

The model equivalents of the three sections defined in Fig. 10 were obtained from FREE and ASSIM outputs. Figure 11 shows the difference in mean temperature along each of the lanes over the period 1993-1998. The depth of the isotherms of the mean temperature field observed by the XBTs is superimposed.

The errors with respect to the three mean temperature sections are significantly reduced, particularly at the thermocline in the equatorial wave guide where the errors of FREE locally exceed $5^{\circ} \mathrm{C}$. This confirms that ASSIM is able to largely correct the error on the mean position of the thermocline. Another interesting observation is that errors with respect to these independent observations were reduced even outside the region controlled by TAO/TRITON data. In this outside region, however, the error reduction is less pronounced than in the equatorial wave guide where the joint assimilation is effective. This last point illustrates the benefit of a multiple data set assimilation with regards to pure altimetric data assimilation.

Along the Central Pacific lane, ASSIM reveals a patch of fairly marked errors at depth, below the $12^{\circ} \mathrm{C}$ isotherm. This patch is localized around $10^{\circ} \mathrm{N}$. If we go back to Fig. 10, it may be seen that this point corresponds to longitude $140^{\circ} \mathrm{W}$, or close to one of the moorings in the TAO/TRITON network $\left(9^{\circ} \mathrm{N}-140^{\circ} \mathrm{W}\right)$. Once again, a specific issue is seen in the $10^{\circ} \mathrm{N}$ area.

\subsection{A GRACE MDT deficiency at around $10^{\circ} \mathrm{N}$ ?}

Then, specific problems arise around $10^{\circ} \mathrm{N}$ in a region of steep meridional MDT gradients associated with the ridge of the NECC. It is also in this region that we had observed the greatest residual errors between the DT and the TAO/TRITON mooring dynamic heights. This led us to suspect a problem of compatibility in this region between the altimetric signal and in-situ data. To better identify the type and distribution of the errors on the simulated MDTs, we calculated the difference between the GRACE MDT on the one hand and the MDTs of FREE and ASSIM on the other. Figure 12 shows the difference maps, on which the locations of
Fig. 12 Differences (in meters) between the GRACE MDT and, respectively, the FREE MDT (top panel) and the ASSIM MDT (bottom panel) for the 1993-1998 period. TAO moorings are located at crosses

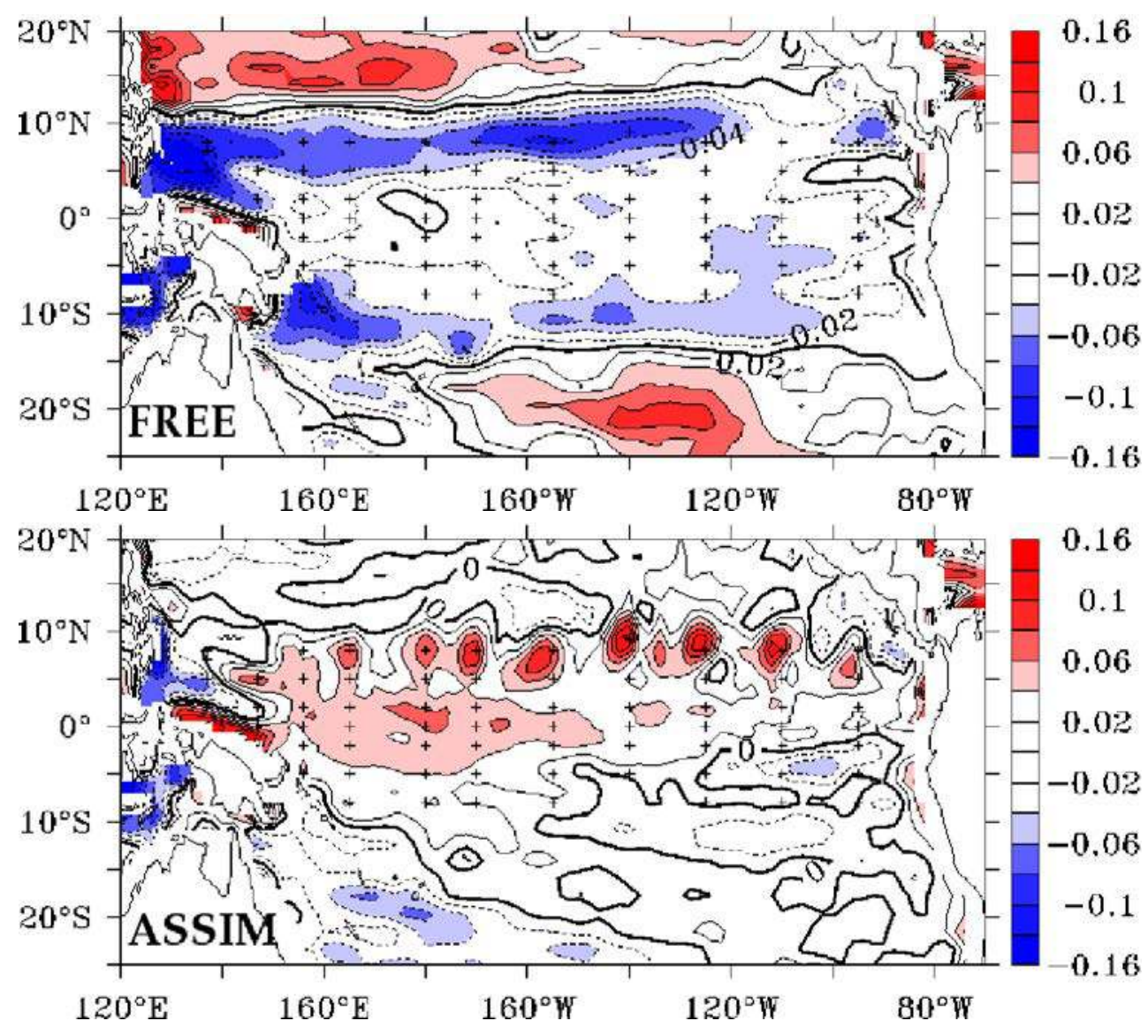


TAO/TRITON moorings are marked by crosses. It may be noted firstly that DA enabled a considerable reduction in the errors over the study area with respect to the GRACE MDT. The RMSD over the entire area was reduced from $4.5 \mathrm{~cm}$ for FREE to only $3.1 \mathrm{~cm}$ for ASSIM. However, Fig. 12 reveals patches of error around certain moorings along $8^{\circ} \mathrm{N}$ longitude. These patches explain the somewhat speckled look of the ASSIM MDT (cf. Fig. 5). The fact that they are systematically located along the vertical of a TAO/TRITON mooring is the signature of a difference of mean state between the altimetric data and the TAO/TRITON in situ profiles. This difference of mean state between the two sets of assimilated data is also illustrated in Fig. 13, which shows two sections of the GRACE, FREE, and ASSIM MDTs. We used section $140^{\circ} \mathrm{W}$, a section sampled by the TAO/TRITON network, and section $145^{\circ} \mathrm{W}$, located between the two TAO/TRITON
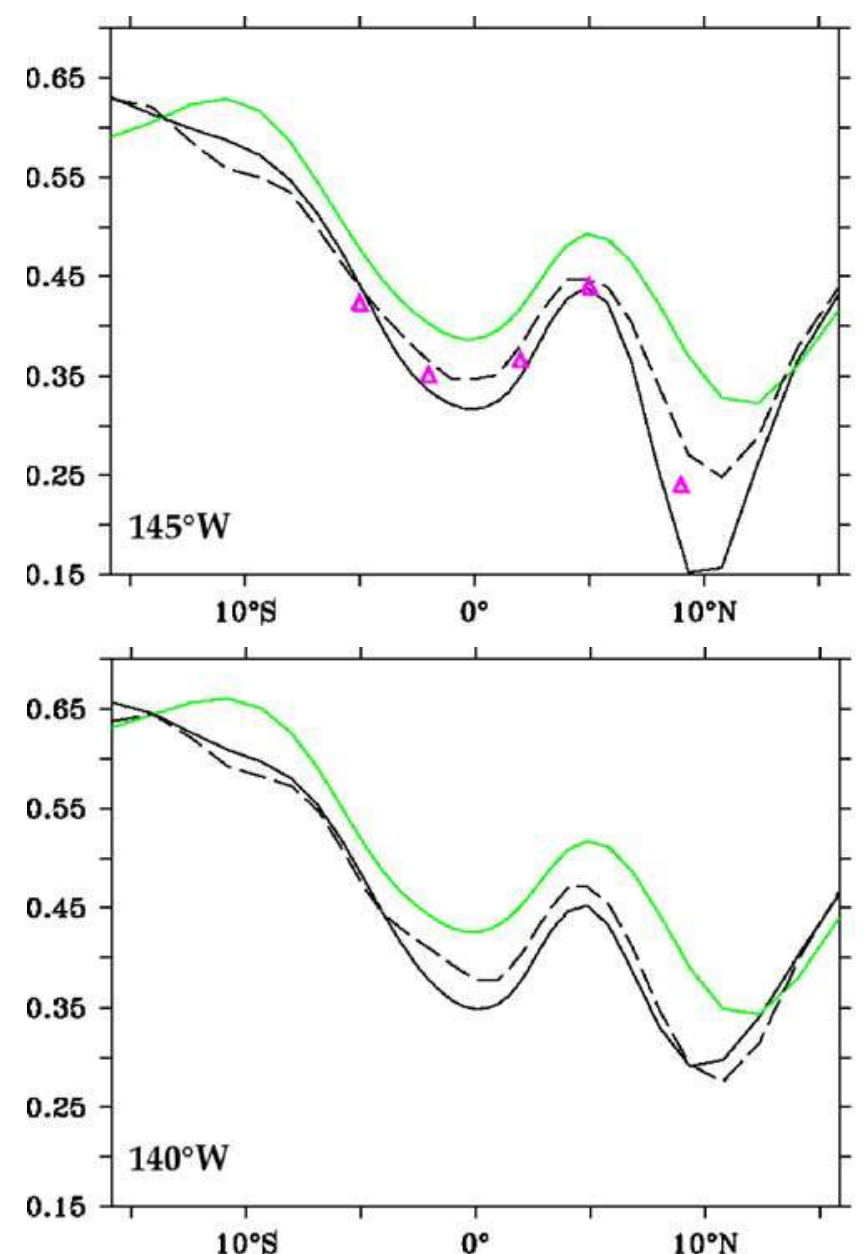

Fig. 13 MDT sections (in meters) for the 1993-1998 period along $145^{\circ} \mathrm{W}$ (top) and $140^{\circ} \mathrm{W}$ (bottom): FREE (green line), ASSIM (black line), and GRACE MDT (black dashed line). The pink triangles for the section along $145^{\circ} \mathrm{W}$ represent the mean TAO/TRITON dynamic height for the same time period sections. For section $140^{\circ} \mathrm{W}$, the mean dynamic heights calculated from TAO/TRITON in situ temperature observations are plotted using pink triangles. The reference level for the dynamic heights is somewhat arbitrary, so that the difference in absolute level is not relevant. However, the dynamic heights provide us with an in situ observation of the meridional gradients of the sea level. Figure 13 clearly shows that the TAO/TRITON dynamic heights are in agreement with the GRACE MDT, except in the region of the ridge associated with the NECC at $9^{\circ} \mathrm{N}$. A likely explanation is that the lack of spatial resolution of the GRACE MDT $(333 \mathrm{~km})$ prevents the steep meridional gradients in this region from being faithfully represented. In brief, our results are contaminated by MDT errors leading to a bias in the altimetric observations in the region of the ridge associated with the NECC (around $9^{\circ} \mathrm{N}$ ), a bias here unveiled by the joint data assimilation of the TAO/TRITON temperature profiles.

At this stage, one could have thought of a possible methodological strategy to solve the issue (e.g., adaptation of the assimilation protocol to account for the specific observation error structure by modifying the $\mathbf{R}_{i}$ matrix accordingly). On the other hand, the assimilation process is revealing of an observational deficiency that is useful for further data processing: a direction is given here for a further geoid refinement and improvement that we considered of interest per se.

\section{Summary and conclusions}

In this paper, we have presented a 6-year hindcast experiment covering the period 1993-1998 and jointly assimilating absolute dynamic topography and in situ temperature profiles into a primitive equation model of the Tropical Pacific. The aim of this study was to implement and analyze over a long pluri-annual period the impact on the simulated dynamics of the Tropical Pacific of this joint assimilation, knowing that absolute DT data set is built using the GRACE satellite geoid as reference.

Although altimetric data and in-situ temperature profiles are extremely complementary, their joint assimilation may be affected by a problem of data compatibility. Given the precision of our knowledge about the MDT, albeit contaminated by errors on the geoid, "disagreement" may exist between the information provided by altimetric observations and that provided by the in situ observations of the TAO/TRITON moorings. This disagreement may prove to be a problem, as demonstrated by $P 03$. This paper confirms that the use of an adequate absolute DT made it possible to 
considerably limit this disagreement and thus provide an appropriate reply to the problems raised by $P 03$.

It is now possible to really benefit from the complementarity that exists between altimetric data, which provide us with a high-resolution, high-precision, and quasisynoptic vision of the ocean surface, and in situ data, which, although rarer, are complementary to altimetric data and are alone capable of providing measurements of the vertical structure.

Apart from a specific region at around $10^{\circ} \mathrm{N}$ where the GRACE MDT is likely and unappropriately too smoothed, the assimilation system set up proved to be very effective. Data assimilation enabled the simulated mean dynamic topography to be made significantly more realistic. The variability of the simulated dynamic topography with data assimilation is also in better agreement with the variability observed by the altimetric satellites. This more faithful representation of the mean dynamic topography of the ocean permits more realistic surface currents, particularly the NEC and the NECC, which were considerably intensified by data assimilation. This intensification is in agreement with the surface current climatology deduced from the SVP drifting buoys proposed by Niiler (2001). Along the vertical, the zonal currents are generally closer to the currents measured by the TAO/TRITON moorings fitted with ADCP sensors along the equator. In particular, the more intensive start up of the EUC in the west of the basin is more realistic. As for temperature, the joint assimilation helped to correctly reposition the thermocline, which was too deep in the free simulation. This improved representation of thermocline depth is confirmed when the simulation with data assimilation is compared with mean temperature sections calculated from independent XBT data.

A 4D view of the ocean dynamic governing this region is available for the 6-year time period and may be pursued longer. In any case, it provides a useful oceanic database for physical interpretations of the dynamics governing interannual variability in the Tropical Pacific region. For example, some studies are underway using this experiment to analyze the near-annual mode (Dewitte et al. 2007), a relatively fast mode of variability with a time periodicity of about $8-18$ months superimposed on the slow cycles dominated by El Niño events, and to investigate integrated quantities such as the warm water volume (i.e., water with temperatures greater than $20^{\circ} \mathrm{C}$ ), which is intrinsically related to the dynamics of the El Niño-southern oscillation cycle (Meinen and McPhaden 2000).

The $10^{\circ} \mathrm{N}$ region is the only region where joint assimilation still poses a few problems. It seems reasonable to hope that the latest MDTs calculated from the EIGEN4 geoid model based on a little more than 2 years of GRACE data will enable a solution to this problem.

With the dedicated gravimetric satellites, altimetry has finally entered a new era. Oceanographers will now be able to fully exploit altimetric signals and to extract the absolute dynamic topography of the ocean rather than just the variable part of the signals. This is already the case for medium and large scales and, with the forthcoming launch of the GOCE mission, will soon be the case for scales down to $100 \mathrm{~km}$. In the context of DA, the use of such an absolute dynamic topography signal opens up numerous perspectives for the development of effective systems based on multiple observation data varying in both nature and spatial or temporal distribution. This latter point is a crucial issue for future operational systems from the point of view not only of understanding the ocean system but also of forecasting its evolution over different time scales.

Acknowledgements This work was supported by the Centre National d'Etude Spatiales (CNES), the Centre National de Recherche Scientifique (CNRS) and the Groupe Mission Mercator Coriolis (GMMC). The research took place as part of the EUfunded MERSEA project under Contract SIP3-CT-2003-502885. We would like to thank in particular Jean-Michel Lemoine (CNES) for providing the so-called GRACE mean dynamic topography. The calculations were conducted with the support of Institut du Developpement et des Ressources en Informatique Scientifique/CNRS.

\section{References}

Alory G, Cravatte C, Izumo T, Rodgers KB (2005) Validation of a decadal OGCM simulation for the tropical Pacific. Ocean Model 10:272-282

Ballabrera-Poy J, Brasseur P, Verron J (2001) Dynamical evolution of the error statistics with the SEEK filter to assimilate altimetric data in eddy-resolving ocean models. Q J R Meteorol Soc 127:233-253

Barnier B, Madec G, Penduff T, Molines J-M, Treguier A-M, Le Sommer J, Beckmann A, Biastoch A, Böning C, Dengg J, Derval C, Durand E, Gulev S, Remy E, Talandier C, Theetten S, Maltrud M, McClean J, De Cuevas B (2006) Impact of partial steps and momentum advection schemes in a global circulation model at eddy permitting resolution. Ocean Dyn 56:543-567, doi:10.1007/ s10236-006-0082-1

Biancale R, Balmino G, Lemoine J-M, Marty J-C, Moynot B, Barlier F, Exertier P, Laurain O, Gegout P, Schwintzer P, Reigber C, Bode A, König R, Massmann F-H, Raimondo J-C, Schmidt R, Zhu S (2000) A new global Earth's gravity field model from satellite orbit perturbations: GRIM5-S1. Geophys Res Lett 27:3611-3614

Bingham RJ, Haines K, Hughes CW (2008) Calculating the ocean's mean dynamic topography from a mean sea surface and a geoid. J Atmos Ocean Technol (in press)

Birol F, Brankart J-M, Castruccio F, Brasseur P, Verron J (2004) Impact of ocean mean dynamic topography on sat- 
ellite data assimilation. Mar Geod 27:59-78, doi:10.1080/ 01490410490475633

Blanke B, Delecluse P (1993) Variability of the tropical atlantic ocean simulated by a general circulation model with two different mixed-layer physics. J Phys Oceanogr 23: 1363-1388

Blayo E, Verron J, Molines JM (1994) Assimilation of TOPEX/Poseidon altimeter data into a circulation model of the North Atlantic. J Geophys Res 99(C12):24691-24705

Blayo E, Mailly T, Barnier B, Brasseur P, Le Provost C, Molines JM, Verron J (1997) Complementarity of ers-1 and topex/poseidon altimeter data in evaluating the oceanic circulation: assimilation in a model of the north atlantic. J Geophys Res 102(C8):18573-18584

Bloom SC, Takacs LL, Da Silva AM, Ledvina D (1996) Data assimilation using incremental analysis updates. Mon Weather Rev 124(6):1256-1271

Brankart J-M, Testut C-E, Brasseur P, Verron J (2003) Implementation of a multivariate data assimilation scheme for isopycnic coordinate ocean models: application to a 1993-96 hindcast of the North Atlantic Ocean circulation. J Geophys Res 108(C3):1-20

Brasseur P, Verron J (2006) The SEEK filter method for data assimilation in oceanography: a synthesis. Ocean Dyn 56 (5-6):650-661, doi:10.1007/s10236-006-0080-3

Brasseur P, Ballabrera-Poy J, Verron J (1999) Assimilation of altimetric observations in a primitive equation model of the gulf stream using a singular evolutive extended Kalman filter. J Mar Syst 22:269-294

Cane MA, Kaplan A, Miller RN, Tang B, Hackert EC, Busalacchi AJ (1996) Mapping tropical Pacific sea level: data assimilation via a reduced state space Kalman filter. J Geophys Res 101:22599-22617

Castruccio F, Verron J, Gourdeau L, Brankart JM, Brasseur P (2006) On the role of the GRACE mission in the joint assimilation of altimetric and TAO data in the tropical pacific ocean model. Geophys Res Lett 33:L14616, doi:10.1029/2006GL025823

de Boyer Montégut C, Vialard J, Shenoi SSC, Shankar D, Durand F, Ethé C, Madec G (2007) Simulated seasonal and interannual variability of mixed layer heat budget in the northern Indian Ocean. J Climate 20:3249-3268

Dewitte B, Illig S, Parent L, du Penhoat Y, Gourdeau L, Verron J (2003) Tropical Pacific baroclinic mode contribution and associated lang waves for the 1994-1999 period from an assimilation experiment with altimetric data. J Geophys Res 108(C4):3121

Dewitte B, Cibot C, Périgaud C, An S-I, Terray L (2007) Interaction between near-annual and ENSO modes in a CGCM simulation: role of the equatorial background mean state. J Climate 20(6):1035-1052, doi:10.1175/JCLI4060.1

Durand F, Gourdeau L, Delcroix T, Verron J (2003) Can we improve the representation of modeled ocean mixed layer by assimilating surface-only satellite-derived data? A case study for the Tropical Pacific during the 1997-1998 El Niño. J Geophys Res 108(C6):3200

Fu L-L, Cazenave A (2001) Satellite altimetry and earth sciences: a handbook of techniques and applications, International Geophisics Series, vol 69. Academic, San Diego

Gourdeau L, Verron J, Delcroix T, Busalacchi AJ, Murtugudde R (2000) Assimilation of Topex/Poseidon altimeter data in a primitive equation model of the tropical pacific ocean, during the 1992-1996 ENSO period. J Geophys Res 105(C5):8473-8488

Gourdeau L, Lemoine J-M, Rio MH, Hernandez F (2003) Estimating mean dynamic topography in the tropical Pacific ocean from gravity and altimetry satellites. Geophys Res Lett 30(20):2062

Grima N, Bentamy A, Katsaros K, Quilfen Y (1999) Sensitivity of an oceanic general circulation model forced by satellite wind stress fields. J Geophys Res 104(C4):7967-7989

Hernandez F, Schaeffer M, Calvez MH, Dorandeu J, Faugre Y, Mertz F (2001) Surface moyenne océanique: support scientifique à la mission altimétrique JASON-1, et à une missions micro-satellite altimétrique, Tech. rep., Contract SSALTO 2945 - Lot 2 - A.1, Rapport n ${ }^{\circ}$ CLS/DOS/NT/00.341

Kessler WS (1990) Observations of long waves in the Northern Tropical pacific. J Geophys Res 95(C4):5183-5217

Le Grand P, Mercier H, Reynaud T (1998) Combining T/P altimetric data with hydrographic data to estimate the mean dynamic topography of the North Atlantic and improve the geoid. Ann Geophys 16:638-650

Le Grand P, Schrama EJO, Tournadre J (2003) An inverse modeling estimate of the dynamic topography of the ocean. Geophys Res Lett 30(2):1062-1065, doi:10.1029/ 2002GL014917

Lemoine F, Kenyon S, Factor J, Trimmer R, Pavlis N, Chinn D, Cox C, Klosko S, Luthcke S, Torrence M, Wang Y, Williamson R, Pavlis E, Rapp R, Olson T (1998) The development of the joint NASA GSFC and the National imagery and mapping agency (NIMA) Geopotential model EGM96, Tech. Rep. NASA/TP-1998-206861, NASA Technical Paper. Goddard Space Flight Center, Greenbelt

Lengaigne M, Boulanger J-P, Menkes C, Masson C, Madec G, Delecluse P (2002) Ocean reponse to the March 1997 westerly wind event. J Geophys Res 107(C12):8015

Lengaigne M, Madec G, Menkes C (2003) Impact of isopycnal mixing on the tropical ocean circulation. J Geophys Res 108(C11):3345

Levitus S, Boyer T (1994) World ocean atlas 1994. Tech. Rep. vol 4: Temperature, NOAA Atlas NESDIS 4. U.S. Gov. Printing Office, Washington, DC

Levitus S, Burgett R, Boyer T (1994) World ocean atlas 1994. Tech. Rep. vol 3: Salinity, NOAA Atlas NESDIS 3. U.S. Gov. Printing Office, Washington, DC

Levitus S, Boyer T, Conkright ME, O' Brien T, Antonov J, Stephens C, Stathoplos L, Johnson D, GR (1998) World ocean atlas 1998 data. Tech. Rep. vol 1: Introduction, MOAA Atlas NESDIS 18. U.S. Gov. Printing Office, Washington, DC

Maximenko N, Niiler P (2005) Hybrid decade-mean global sea level with mesoscale resolution. In: Saxena N (ed) Recent advances in marine science and technology. Pacon, Honolulu, pp 55-59

McPhaden M, Busalacchi AJ, Cheney R, Donguy JR, Gage KS, Halpern D, Ji M, Julian P, Meyers G, Mitchum GT, Niiler PP, Picaut J, Reynolds RW, Smith N, Takeuchi K (1998) The tropical ocean-global atmosphere observing system: a decade of progress. J Geophys Res 103:14169-14240

Meinen CS, McPhaden MJ (2000) Observations of warm water volume changes in the equatorial pacific and their relationship to El Niño and La Niña. J Climate 13(20):3551-3559

Menkes C, Boulanger J, Busalacchi A, Vialard J, Delecluse P, McPhaden MJ, Hackert E, Grima N (1998) Impact of TAO vs. ERS wind stresses onto simulations of the tropical Pacific Ocean during the 1993-1998 period by the OPA OGCM. In: Climate impact of scale interaction for the tropical oceanatmosphere system, vol 13. Euroclivar Workshop Report, Paris, 14-16 September 1998

Mercier H (1986) Determining the general circulation of the ocean: a non-linear inverse problem. J Geophys Res 91: 5103-5109 
Nerem RS, Schrama EJ, Koblinsky CJ, Beckley BD (1994) A preliminary evaluation of ocean topography from the TOPEX/POSEIDON mission. J Geophys Res 99(C12): 24565-24583

Nerem RS, Jekeli C, Kaula WM (1995) Gravity field determination and characteristics retrospective and prospective. J Geophys Res 100(B8):15053-15074

Niiler P (2001) The world ocean surface circulation, international geophysics series. In: Siedler G, Church J, Gould J (eds) Ocean circulation and climate, vol 77. Academic, New York

Niiler PP, Maximenko NA, McWilliams J (2003) Dynamically balanced absolute sea level of the global ocean derived from near-surface velocity observations. Geophys Res Lett 30(22):2164

Ourmières Y, Brankart J-M, Berline L, Brasseur P, Verron J (2006) Incremental analysis update implementation into a sequential ocean data assimilation system. J Atmos Ocean Technol 23(12):1729-1744

Parent L, Testut C-E, Brankart J-M, Verron J, Brasseur P, Gourdeau L (2003) Comparative assimilation of Topex/ Poseidon and ERS altimeter data and of TAO temperature data in the Tropical Pacific Ocean during 1994-1998, and the mean sea-surface height issue. J Mar Syst 40-41:381401

Pham DT, Verron J, Gourdeau L (1998a) Filtre de kalman évolutif pour l'assimilation de données en océanographie. Comptes Rendus Acad Sci 326(4):255-260

Pham DT, Verron J, Roubaud MC (1998b) Singular evolutive extended Kalman filter with EOF initialization for data assimilation in oceanography. J Mar Syst 16:323-340

Reigber C, Schmidt R, Flechtner F, König R, Meyer U, Neumayer K-H, Schwintzer P, Yuan Zhu S (2005) An Earth gravity field model complete to degree and order 150 from GRACE: EIGEN-GRACE02S. J Geodyn 39(1):1-10

Rio M-H, Hernandez F (2004) A mean dynamic topography computed over the world ocean from altimetry, in situ measurements, and a geoid model. J Geophys Res 109(C12032), doi:10.1029/2003JC002226

Rio M-H, Schaeffer P, HF, Lemoine J-M (2006) From the altimetric sea level measurement to the ocean absolut dynamic topography: mean sea surface, geoid, mean dynamic topography, a threecomponent challenge. In: Proceedings of the Symposium ń 15 years of progress in radar altimetry $\dot{z}$, Venice, 16-18 March 2006, ISBN: 92-9092-925-1 ISSN : 1609042X, p 6

Roulet G, Madec G (2000) Salt conservation, free surface, and varying levels: a new formulation for ocean general circulation models. J Geophys Res 105(C10):23927-23942

Smith RD, Maltrud ME, Bryan FO, Hecht MW (2000) Numerical simulation of the North Atlantic ocean at $1 / 10^{\circ}$. J Phys Oceanogr 30:1532-1561

Testut C-E, Brasseur P, Brankart J-M, Verron J (2003) Assimilation of sea-surface temperature and altimetric observations during 1992-1993 into an eddy permitting primitive equation model of the North Atlantic Ocean. J Mar Syst 40-41: 291-316

Verron J, Gourdeau L, Pham DT, Murtugudde R, Busalacchi AJ (1999) An extended Kalman filter to assimilate satellite altimeter data into a non-linear numerical model of the Tropical Pacific: method and validation. J Geophys Res 104: 5441-5458

Xie P, Arkin P (1996) Analyses of global monthly precipitation using gauge observations, satellite estimates, and numerical model predictions. J Climate 2:840-858 